\title{
Los riesgos de la vulnerabilidad sociodemográfica por el Covid-19 en México 2020
}

\section{The risks of sociodemographic vulnerability due to Covid-19 in Mexico 2020}

\author{
Juan Gabino González-Becerril \\ Bernardino Jaciel Montoya-Arce
}

\author{
Centro de Investigación y Estudios Avanzados de la Población \\ de la Universidad Autónoma del Estado de México, México
}

\begin{abstract}
Resumen
En México recién habíamos concluido un año de la transición política y con muchos cuestionamientos acerca de la administración de la autodenominada cuarta transformación se encaminaba a una crisis económica, pero surge el Covid- 2019, la cual se profundiza y es acompañada por una dificultad de salud pública en el mundo (un hecho social sistémico en tiempos de tempestades que requiere ser pensada, repensada e impensada). En este contexto se inscribe este ensayo en el que planteamos como objetivo hacer una reflexión sobre un tema, al cual se le dio seguimiento en tiempo real en los últimos ocho meses (marzo-octubre de 2020) y que, desde la sociodemogafía, podemos revisar sus causas y consecuencias sociales en México, el cual creó psicosis e incertidumbre en todos los ámbitos del mundo y en específico en nuestro país, así como en el Estado de México.
\end{abstract}

Palabras clave: Vulnerabilidad demográfica, riesgo, Covid-19, crisis del sistema demográfico, crisis económica, crisis de salud, movilidad e inmovilidad.

\section{Abstract}

In Mexico we had just concluded a year of political transition and with many questions about the administration of the self-proclaimed fourth transformation, it was heading towards an economic crisis but, Covid-2019 arises, which is deepening and is accompanied by a public health difficulty in the world (a systemic social fact in times of storms that requires to be thought, rethought and unthinkable). In this context, this essay is inscribed in which we propose as an objective to make a reflection on a topic, which was followed in real time in the last eight months (March-October 2020) and that, from the sociodemography we can review its causes and social consequences in Mexico, which created psychosis and uncertainty in all areas of the world and specifically in our country as well as in the State of Mexico.

Keywords: Demographic vulnerability, risk, Covid-19, crisis of the demographic system, economic crisis, health crisis, mobility and immobility. 


\section{INTRODUCCIÓN}

$\mathbf{D}$ esde el inicio de la pandemia nos propusimos dar seguimiento a través de los distintos medios de comunicación y las fuentes estadísticas del país, así como de su evolución, comportamiento, causas y consecuencias del Covid-19 sobre el sistema demográfico. Las opiniones polarizadas en nuestro país (hasta hoy, los adversarios del presidente López Obrador), unos defendiendo la postura gubernamental, otros haciendo leña de ella, a la vez que los expertos sobre salud consideran este año: como el año de la peste por lo mal que se manejó la atención a la salud de los mexicanos. Pareciera que todo mundo tenía la razón y, lo más lamentable, es que quedarse en casa significó la inmovilidad sistémica que para muchos no entendieron y otros tantos no siguieron las recomendaciones de la Secretaría de Salud del país. Porque, quienes sí se quedaron en casa son en su mayoría la burocracia cuya conducta está regida por un sistema de reglas técnicas y normas de tipo general y consiste en la aplicación de esas reglas a cada caso y situación concreta, ${ }^{1}$ ellos son quienes gozan de ingresos económicos garantizados (las alusiones a la burocracia como órgano tienen un carácter instrumentalista, profundizado, además, es un ente que permite la intervención de la política pública en coyunturas que la vuelven urgente, como es el caso de la emergencia del Covid-19) ${ }^{2}$ y los millones de informales profundizan su exposición a enfermarse y entrar en crisis en forma muldimensional y su sobrevivencia es uno de los grandes desafíos en este contexto de la pandemia. ${ }^{3}$

La enfermedad del Covid-19 significó un freno o la inmovilidad para el sistema demográfico (en la movilidad humana, no así para la mortalidad y la fecundidad) y la economía a causa del contagio masivo de dicha enfermedad y una exposición de mayor riesgo para toda la población y en específico por parte de los informales debido a su exposición-riesgo y escasa capacidad de respuesta ante la pandemia, aunque al inicio, algunos afirmaban que, a quienes se contagiara, en un inicio, su probabilidad era como sacarse la lotería nacional, es decir, una probabilidad muy remota. Otros, sostenían en sus proyecciones, que ocurrirían hasta dos mil fallecimientos (o el tope de los 60 mil fallecimientos lo consideraban como catastrófico),

\footnotetext{
1 Santiago Martínez Castilla, 2016, La burocracia: elemento de dominación en la obra de Max Weber, disponible en dialnet.unirioja.es, descarga articulo (06/04/2020).

2 Antonio Olivé, 2017, Burocracia y teoría marxista del estado, disponible en https://kmarx. wordpress.com/2017/03/06/burocracia-y-teoria-marxista-del-estado/ (06/04/2020).

3 CEPAL, 2020, Cepal: México debe dar giro en política fiscal por Covid-19, disponible en https:/www.jornada.com.mx/ultimas/economia/2020/04/04/cepal-mexico-debe-dar-giro-en-politica-fiscal-por-covid-19-1989.html (06/04/2020).
} 
en tanto que el Instituto Mexicano de Seguridad Social (IMSS) sostenía que serían 42 mil y en tanto que la Secretaría de Salud en su versión estenográfica declaraba que sería miles y cuya forma sería la de una montaña al final de la fase tres en abril o mayo del 2020. Lo cierto es que llegamos al mes de agosto de 2020 con la cifra catastrófica mayor a las 60 mil defunciones por Covid-19 en México y no tiene para cuando la disminución (que hasta el mes de septiembre ya se mencionaba el rebrote) ${ }_{,}^{4}$ aunque la Organización Mundial de la Salud (OMS), había declarado una desaceleración, pero manifestando su preocupación por el rebrote en los países europeos de la pandemia. ${ }^{5}$ Una respuesta ante la vulnerabilidad sistémica demográfica-social, la producción y la distribución de la vacuna sería un gran alivio, la cual se pronostica que sea para el primer trimestre del año 2021 y en la cual el Gobierno de México colabora con algunos proyectos médicos para incidir en la pandemia de mayor alcance de todos los tiempos (que por cierto en noviembre ya se aplicaban algunas pruebas en entidades seleccionadas por la autoridad gubernamental).

Para lograr nuestros objetivos el texto se organiza de la siguiente manera: exponemos de inicio la teoría de la vulnerabilidad sociodemográfica-social (con su agregado de la inmovilidad) y causas del Covid-19; antecedentes de la pandemia; metodología y análisis de resultados, así como de comentarios finales a nuestro ensayo.

\section{Teoría del SURgimiento, CAUSAS Y CONSECUENCIAS DE LA TRANSMISIÓN DEL SARS-CoV-2}

La Organización Mundial de la Salud (OMS) sostiene que los coronavirus son una familia de virus que pueden causar enfermedades como el resfriado común, el síndrome respiratorio agudo grave (SARS, por sus siglas en inglés), y el síndrome respiratorio de Oriente Medio (MERS, por sus siglas en inglés). En 2019 se identificó un nuevo coronavirus como la causa de un brote de enfermedades que se originó en China (con sus variantes en el tiempo). Este virus ahora se conoce como el síndrome respiratorio agudo grave coronavirus 2 (SARS-CoV-2). La enfermedad que causa se llama enfermedad del coronavirus 2019 (Covid-19). En marzo de 2020 la Organización Mundial de la Salud (OMS) declaró que este brote de Covid-19

\footnotetext{
${ }^{4}$ Véase en "Las predicciones no son promesas, afirma López Gatell; no descarta rebrotes", consultado en https://www.excelsior.com.mx/nacional/las-predicciones-no-son-promesasafirma-lopez-gatell-no-descarta-rebrotes/1406841 (21/09/2020).

5 Véase en "Europa sufre un rebrote grave de contagios de Covid-19, dice la OMS", consultado en https://cnnespanol.cnn.com/video/covid-contagios-situacion-grave-oms-europa-panorama-mundial-maria-alejandra-requena/ (21/09/2020).
} 
es una pandemia. Las organizaciones de salud pública de los gobiernos del mundo incluyendo la de México, así como los Centros para el Control y la Prevención de Enfermedades de los Estados Unidos (CDC) y (OMS) están vigilando la pandemia y publicando actualizaciones en sus sitios web de manera cotidiana. Estos grupos también han publicado recomendaciones para prevenir y tratar esta enfermedad. ${ }^{6}$ El virus se acelera cada vez más. El Covid-19 es diez veces más letal que la pandemia por A-H1N1: según la $\mathrm{OMS}^{7}$ (Quiroga, 2020).

Inmediatamente que surgió el Covid-19, se platearon diversas teorías acerca de su origen como derivado del neoliberalismo globalizador que nos conduce a la desglobalización (y sus desencantos), ${ }^{8}$ la dictadura sanitaria y la vigilancia corporativa generalizada, ${ }^{9}$ del socialismo, teoría de la conspiración (por ejemplo, el presidente de Estados Unidos ha manifestado que dicho virus fue creado en un laboratorio de China) ${ }^{10}$ la pandemia y el sistema mundo, poshumanismo y transhumanismo (Postigo, 2011; Torralba, 2018; Armesilla, 2018; Patiño, 2020), la teoría de riesgos, teoría epidemiológica, crisis civilizatoria u otra fuente poco creíble, sin embargo, investigadores serios han concluido que se originó a través de procesos naturales y no fue creado en un laboratorio (que por otro lado hay quienes sostienen que sí). ${ }^{11}$

\footnotetext{
${ }^{6}$ Véase en Enfermedad del coronavirus 2019 (Covid-19), disponible en https://www.mayoclinic.org/es-es/diseases-conditions/coronavirus/symptoms-causes/syc-20479963 (06/04/2020).

${ }^{7}$ Quiroga, Ricardo, Covid-19 es diez veces más letal que la pandemia por A-H1N1: OMS, consultado en https://www.eleconomista.com.mx/arteseideas/Covid-19-es-diez-veces-mas-letalque-la-pandemia-por-A-H1N1-OMS-20200413-0055.html (26/04/2020).

${ }_{8}$ Richard N. Haass, 2020, La desglobalización y sus desencantos, disponible en https://www. eleconomista.com.mx/opinion/La-desglobalizacion-y-sus-desencantos-20200513-0138.html $(14 / 05 / / 2020)$. Pero hay quienes sostiene que convendría concentrarse en minimizar una disrupción que sería propiciada por el próximo periodo de desglobalización y sentar las bases para un proceso más sostenible a partir de entonces, Mohamed A. El-Erian, Navegando la Desglobalización, disponible en https://www.eleconomista.com.mx/opinion/Navegando-la-Desglobalizacion-20200511-0151.html (16 de mayo de 2020). Un ejemplo de la desglobalización es el retiro de Gran Bretaña, EU da un paso más hacia el aislacionismo sobre el tema del Tratado de Cielos Abiertos, entre otros, disponible en https://www.eleconomista.com.mx/revistaimef/EU-da-unpaso-mas-hacia-el-aislacionismo-20200521-0154.html (26/05/2020).

9 Véase García Canclini, 2020, La dictadura sanitaria por el coronavirus y la vigilancia corporativa generalizada, https://urbanalogia.blogspot.com/2020/04/garcia-canclini-la-dictadura-sanitaria.html?fbclid=IwAR3NY3frKm_AF_vLDn-DRTDRJbDKUv6b_PejmFXnN5GvkmgKpbnYH-OBFHg $(10 / 05 / 2020)$.

${ }_{10}$ Pero la CIA desmonta la teoría de la conspiración china de Trump sobre el origen del Covid-19, https: //www.google.com/search? $\mathrm{q}=$ trump $+\mathrm{y}+$ covid $+19 \% 2 \mathrm{C}+$ conspiraci $\% \mathrm{C} 3 \% \mathrm{~B} 3 \mathrm{n}+\mathrm{de}+$ china\&oq $=$ trump $+\mathrm{y}+$ covid $+19 \% 2 \mathrm{C}+$ conspiraci $\% \mathrm{C} 3 \% \mathrm{~B} 3 \mathrm{n}+\mathrm{de}+$ china\&aqs $=$ chrome...69i57.27029j$0 j 8 \&$ sourceid $=$ chrome\&ie $=U T F-8(07 / 05 / 2020)$. Pero 7 de cada 10 estadounidenses culpa al gobierno chino por defunciones, en https://www.eleconomista.com.mx/politica/7-de-cada-10-estadounidenses-culpa-al-gobierno-chino-por-defunciones-20200512-0052.html

${ }_{11}$ Por ejemplo, "No procede de la naturaleza': viróloga dice que China creó covid-19", consultado en https://www.eltiempo.com/vida/ciencia/virologa-china-asegura-que-el-coronavirus-no-proviene-de-la-naturaleza-524040 (25/09/2020).
} 
Para fines de este trabajo se utiliza el enfoque de la teoría de la vulnerabilidad social-demográfica cuya ecuación se sintetiza en la exposición a riesgos y la incapacidad de respuesta; asimismo, la vulnerabilidad es igual a la exposición a riesgos más la incapacidad para enfrentarlos, más la inhabilidad (que se acompaña de la inmovilidad) ${ }^{12}$ para adaptarse activamente con dicha enfermedad (Rodríguez, 2000); dichos argumentos son apoyados por el trabajo de Ulrich Beck (1998) el cual sintetizó en su difundido libro La sociedad del riesgo: hacia una nueva modernidad (el cual argumenta que el riesgo lleva implícito la condición dialéctica de progreso y riesgo).

El concepto de vulnerabilidad social se define como un proceso multidimensional y dinámico que confluye en el riesgo de un individuo o comunidad de ser afectado o dañado por cambios o situaciones internas y externas y, su capacidad para enfrentar las adversidades. Los estudios tradicionales de la vulnerabilidad social han explorado las dimensiones económicas, políticas, jurídicas, demográficas, ambientales y de salud, entre otras, prestando atención a factores asociados a la fragilidad, inseguridad y el desamparo institucional de determinados individuos y comunidades (Sánchez y Egea, 2010: 1).

Lo anterior (la vulnerabilidad social o vulnerabilidad macro), se puede ejemplificar en el contexto de la pandemia con la sucesión de pequeñas (y no tan pequeñas) crisis económicas; el aumento de la volatilidad del Producto Interno Bruto (PIB) y del consumo de los hogares; el persistente incremento de la pobreza; el empeoramiento de los cuellos de botella que impiden generar puestos de trabajo de buena calidad y, en general, el deterioro laboral, expresado en altos índices de desempleo, menor protección e incremento de diversas formas de precariedad; los pertinaces rezagos en materia de calificación de recursos humanos y de capacidad para absorber y generar progreso técnico, que redundan en una enorme dificultad para sustentar la competitividad en fundamentos virtuosos; el efecto devastador de numerosos desastres naturales (corriente de El Niño, huracanes, sismos); los graves estallidos sociales, que se distinguen de los pretéritos por una creciente carencia de conducción política organizada; el incremento de la inseguridad cotidiana reflejado en altos índices —objetivos y subjetivos - de criminalidad y temor; la desafección a la política, las formas de

12 Primero "la movilidad es un componente de la inmovilidad y viceversa. La condición de estar en movimiento produce fricciones, frenos o entrampamientos (ej. confinamiento, cuarentena, controles de paso, detención); y, del mismo modo, el movimiento se origina a partir de una condición estática (ej. aumento de la movilidad social mediante las tecnologías en estado de inmovilidad física, o la movilidad permitida mediante medidas de des-confinamiento); segundo, consiste entonces en comprender cómo las (in)movilidades del virus interactúan con la producción de (in) seguridades, el lugar epistemológicamente valioso para ello es la intersección" (Iranzo, 2020: 65) 
acción colectivas y las instancias históricas de representación social, como los sindicatos y los partidos políticos; el agravamiento de conflictos políticos que estrechan las bases de legitimidad de las autoridades nacionales, pudiendo llevarlas, en su expresión más dramática, al término anticipado de su gestión, y que tampoco dejan indemnes a los sistemas de gobierno, respecto de los cuales crecen la desconfianza y el escepticismo por su incapacidad de dar respuesta al riesgo de enfermarse. Pero todo ello derivado de la inmovilidad o confinamiento de la población se reduce su capacidad de respuesta y fragilidad mayor ante el desamparo de las instituciones nacionales e internacionales.

Una de estas dimensiones (macro), citadas, podemos agregar el de la vulnerabilidad del sistema demográfico, ${ }^{13}$ la cual se expresa en las familias y la del individuo, en el cual el planteamiento incluye "la capacidad de crianza (que en la ecuación demográfica es la fecundidad, el cual también es afectado por la inmovilidad o lo que se le denominó confinamiento, ${ }^{14}$ el cual para algunos fue privilegio y para otros castigo), en cuyos rasgos pueden ser agrupados en tres dimensiones de las unidades domésticas: i) pautas de estructuración; ii) ciclo de vida y, iii) condiciones demográficas básicas (Rodríguez, 2000). Un segundo es la de la mortalidad la cual es denominado pasivos demográficos para explicar la vulnerabilidad entre ellos encontramos la sobremortalidad, la sobrefecundidad y la alta dependencia demográfica, los cuales "implican costos monetarios y no monetarios porque dificultan la adquisición de activos" (Rodríguez, 2004: 8). De ellos se derivan "otros pasivos sociodemográficos como son la reproducción temprana; la concentración de los pobres dentro de las ciudades; la inestabilidad y las fracturas familiares" (Rodríguez, 2004: 8). El enfoque de vulnerabilidad puede ser aplicado a individuos, en particular a migrantes internos e internacionales (que también entraron a una situación de inmovilidad por la pandemia), más aún cuando se vulneran sus derechos lo que se expresa en la carencia de poder (Bustamante, 2002, sostiene que la vulnerabilidad

\footnotetext{
${ }^{13}$ Massimo Livo Bacci, 1993, sostiene que los componentes de la reproducción del sistema demográfico son: los nacimientos, las muertes y las entradas y salidas por migraciones. A partir de este "núcleo" teórico básico se sintetiza en la llamada ecuación compensadora, véase en Qué es la demografia, consultado en https://apuntesdedemografia.com/curso-de-demografia/ que-es-la-demografia/ (2904/2021).

${ }_{14}$ Aunque para algunos el confinamiento es un concepto" burgués". La idea es que todos tengamos una casa individual, un poco burguesa, en la que podamos refugiarnos cuando haya una pandemia o un desastre natural, pero no todos cuentan con una vivienda, consultado en (https://www.bbc.com/mundo/noticias-internacional-52216492?at_campaign=64\&at_custom $2=$ facebook page \&at custom $3=\mathrm{BBC}+\mathrm{News}+\mathrm{Mundo} \&$ at custom $1=\% 5 \mathrm{Bpost}+$ typ $\mathrm{e} \%$ 5D\&at custom4=BD 5872 $\mathrm{B} 8-79 \mathrm{AE}-11 \mathrm{EA}-\mathrm{A} 1 \mathrm{~B} 8-4 \mathrm{E} 23933 \mathrm{C} 40 \overline{0} \mathrm{C} \&$ at medium=custom7\&fbclid=IwAR2d373ZP5BgMr6oIuCYrKbSjPQJmARgpPISvWy8Uwiceb2Qq6KIcUwya3w\# $(04 / 09 / 2020)$.
} 
es expresado por la exclusión y discriminación en el marco de sistemas sociales con una distribución asimétrica de poder); a actores económicos en sentido amplio cuando se analiza la vulnerabilidad de un determinado patrón de desarrollo a partir del sentimiento de indefensión que emana de la carencia de base material (e inmovilizado); a personas y hogares cuando se habla de vulnerabilidad y pobreza a partir del riesgo de caer por debajo de la línea de pobreza o cuando se trata de la vulnerabilidad de los choques económicos por incapacidad de resistir los impactos de las crisis económicas (como la crisis de la pandemia del Covid-19 que los condujo a una situación de inmovilidad); a los hogares al analizar la vulnerabilidad ante la movilización e in-movilización de activos por carencia de activos o incapacidad para movilizarlos o inseguridad y sensibilidad de los actores frente a cambios del entorno, así como en el análisis de la vulnerabilidad de la estructura de oportunidades por desajuste entre activos y estructura de oportunidades (Araujo, 2015). Desde el punto de visa de la vulnerabilidad el concepto de riesgo constituye un fundamento metodológico esencial de las ciencias demográficas y la salud. Si bien el riesgo indica la probabilidad de ocurrencia de los nacimientos, de la mortalidad (o sobremortalidad por la pandemia) y de la migración, pero también de contraer la enfermedad, en este caso la vulnerabilidad es un indicador de inequidad y de desigualdad a la hora de contraer el Covid-19. Aquí quizás radica la dificultad principal de las ciencias demográfica y de la salud, ya que, utilizando el concepto de riesgo como fundamento de su arsenal teórico-metodológico, no utiliza suficientemente el concepto de vulnerabilidad (hoy vulnerabilidad múltiple y la inmovilidad: macro y micro), pues se dedica más al análisis de la probabilidad de ocurrencia que al de las inequidades y de las desigualdades sociales producto de la inmovilidad sistémica (Araujo, 2015).

Para el caso de la migración o movilidad-inmovilidad de la población se sostiene que los emigrantes-inmigrantes y los de tránsito (que también entraron en un lapso de inmovilidad, algunos sostienen que al menos tres meses) marzo, abril, mayo de 2020 la población estuvo expuesta a la inmovilidad pero su vulnerabilidad al enfermarse de Covid-19 es mayor para ellos y para el resto de la población. ${ }^{15}$

${ }^{15}$ Véase en "Los inmigrantes son al menos dos veces más vulnerables a infectarse de Covid-19 que el resto de la población: OCDE", consultado en https://www.eleconomista.com.mx/internacionales/Los-inmigrantes-son-al-menos-dos-veces-mas-vulnerables-a-infectarse-de-Covid-19que-el-resto-de-la-poblacion-OCDE--20201019-0024.html (19/10/2020). 


\section{Antecedentes de la Pandemia del Covid-19}

La historia económica y la demográfica han atestiguado las grandes epidemias (salud) que han afectado a la población mundial con la única diferencia de que no se había padecido una inmovilidad global. Lo que la demografía históricamente ha hecho, es registrar la "guerra de números" y la multiplicidad de causas, la capacidad de respuesta de la población y consecuencias económicas de dichas pandemias en el curso de la historia. La demografía ha observado pueblos o regiones (distancia geográfica y contagio), analizando una multiplicidad de factores, su interrelación con los procesos demográficos (nacimientos, defunciones y migraciones), sus consecuencias, en los cambios sociales, tecnológicos y en el ecosistema en el mundo (Livi Bacci, 2012).

Enseguida se enlistan algunos ejemplos de las epidemias que ha afrontado la humanidad: 1) Peste Negra (Siglo XIV); 2) Gripe Española (19181920); 3); La Gripe Asiática (1957); 4) La Gripe de Hong Kong (19681969); 5) El VIH-SIDA desde 1980; 6) El Síndrome de las Vacas Locas (1990); 7) La Viruela; 8) El Cólera; 9) La Gripe Aviar (2003); 10) Influenza AH1N1 (2009); y 11) El Covid-19 (Livi Bacci; 2012).

Resulta difícil sintetizar la historia de las epidemias en el mundo y en México, pero podemos sugerir que se revise a la "Historia de las epidemias del México antiguo. Algunos aspectos biológicos y sociales" de Mandujano y sus coautores (2003), los cuales hacen un gran recorrido de dicha época. En una apretada síntesis, nos ubicaremos en tiempos más recientes, es decir, a inicios del siglo XX, Márquez y Molina indican que:

La guerra, el hambre, la pobreza y las epidemias fueron responsables de un estancamiento o "detenimiento demográfico". De acuerdo con los censos de 1910 y 1921, la población de México pasó de 15’160,369 a 14’334,780 de habitantes. La emigración, la guerra civil y la pandemia de influenza fueron responsables de la muerte de 450 mil personas. Hay diversas estimaciones sobre las pérdidas de vida provocadas por la guerra y la epidemia de 1918, una de ellas cuenta dos millones de habitantes muertos por los conflictos armados y 300 mil por la influenza (Márquez y Molina, 2009: 122).

Tres décadas más tarde, de 1940 a 1955, las epidemias del paludismo y la poliomielitis hacen presencia (CONAPRED, 2018):

a. 1940. El paludismo dejó 24 mil muertes por año hasta finales del siglo XX. En 2002 se declaró erradicada. 
b. 1948-1955. La poliomielitis, se registraron 1,100 casos. Se erradicó por medio de la vacunación.

c. 2009. La Influenza A/H1N1. Virus de origen porcino. La pandemia de influenza A-H1N1 marcó la primera década del siglo XXI como una primera pandemia del dicho siglo. Este virus se presentó primero en Perote, Veracruz, y, después, su contagio se extendió por todo México. Asimismo, se extendió a varios países en marzo de 2020, día en que la OMS declaró que el mundo se encontraba ante una pandemia.

Todos estos acontecimientos han significado un freno (o cambio-inmovilidad-movilidad) al crecimiento demográfico en el mundo, así como en nuestro país. Según Massimo Livi Bacci en su libro Historia Mínima de la Población Mundial, versión 2012, en tiempos normales del siglo XVI la mortalidad era de 30 por ciento y en crisis epidémica aumentaba tres veces respecto a los tiempos normales. Con la pandemia del Coronavirus, hoy la tasa de mortalidad en Italia a causa del coronavirus se convirtió en la más alta del mundo: más de ocho por ciento de los casos confirmados, de acuerdo con datos del gobierno italiano. Por otra parte, según la Organización Mundial de la Salud (OMS), en China, el rango de víctimas fatales está entre dos y cuatro por ciento, pero fuera del país asiático la tasa se reduce a 0.7 por ciento, en este caso Italia se sale de dicho rango. ${ }^{16}$

La enfermedad del coronavirus 2019 (Covid-19) es una afección respiratoria que se puede propagar de persona a persona. El virus que causa el Covid-19 es un nuevo coronavirus que se identificó por primera vez durante la investigación de un brote en Wuhan, China. Sí. El Covid-19 se está propagando de persona a persona en distintas partes del mundo. El riesgo de infección con Covid-19 es mayor en las personas que son contactos cercanos de alguien que se sepa que tiene el Covid-19, por ejemplo, trabajadores del sector de la salud o miembros del hogar. Otras personas con un riesgo mayor de infección son las que viven o han estado recientemente en un área con propagación en curso del Covid-19. ${ }^{17}$

La respuesta familiar-individual a la pandemia: para prevenir la propagación de la enfermedad respiratoria a los demás, debería hacer lo siguiente: a) quedarse en casa si está enfermo; b) cubrirse la nariz y la boca con un pañuelo desechable al toser o estornudar y c) luego botarlo a la basura;

16 BBC News Mundo, 2020, Coronavirus: qué hay detrás del alto número de muertes en Italia a causa del covid-19 (20/08/2020).

17 Véase en "Lo que usted debe saber acerca del Covid-19 para protegerse a usted y a los demás", consultado en https://www.cdc.gov/coronavirus/2019-ncov/downloads/2019-ncov-factsheet-sp. pdf $(20 / 10 / 2020)$. 
y limpiar y desinfectar los objetos y las superficies que se tocan frecuentemente, etcétera.

El protocolo institucional: El Grupo Banco Mundial está trabajando activamente con diversas instituciones internacionales y autoridades nacionales para ayudar a coordinar la respuesta mundial (la inmovilidad sistémica); la cuarentena, cierre de fronteras, disminución de viajes, evitar contactos (distancia social saludable), proteger a la población vulnerable (niños, adultos mayores, enfermos crónicos etc.). ${ }^{18}$

Los costes socioeconómicos derivados de la enfermedad viral van más allá de los daños directos en los sectores sociales y económicos afectados en el mundo derivado de la pandemia y la inmovilidad. Sus consecuencias económicas se han multiplicado con rapidez, cuya expresión en México y el mundo es la caída de la Bolsa Mexicana de Valores, disminución en los pronósticos del crecimiento económico, caída del precio internacional del petróleo y del empleo, etcétera. A la vez que se asocia a la pérdida de millones de personas por esta enfermedad, que según los científicos aún no cuenta con una cura efectiva y según proyecciones ira en aumento. ${ }^{19}$

A esto se suma el costo demográfico, específicamente en la fecundidad, en el exceso de la mortalidad y se suma la de la migración interna e internacional a tal grado que países desarrollados han restringido la entrada de personas por esta vía (terrestre, aérea y marítima), los ejemplos son múltiples, el caso de Estados Unidos es importante en este sentido, por un lado, pausará redadas contra migrantes indocumentados por Covid-19, y por otro, un mayor control de sus fronteras y vuelos creando caos en los principales aeropuertos de Estados Unidos debido a los controles por el coronavirus. ${ }^{20}$

México ha tenido avances en el riesgo-vulnerabilidad y capacidad de respuesta pandémica, pero en ocasiones ha rebasado a los países europeos y ocupado los primeros lugares en América Latina en relación a la pobla-

\footnotetext{
18 Julia Barajas y Melissa Etehad, 2020, CORONAVIRUS: Cómo decir hola sin tener contacto físico, consultado en https:/www.latimes.com/espanol/vida-y-estilo/articulo/2020-03-15/coronavirus-como-decir-hola-sin-tener-contacto-fisico (18/06/2020).

19 Véase en El Financiero, 2020, Coronavirus, el alto costo económico de no querer ver, consultado en https:/www.elfinanciero.com.mx/bloomberg-businessweek/coronavirus-el-alto-costo-economico-de-no-querer-ver/ (27/08/2020).

20 Yolanda Monge, 2020, Caos en los principales aeropuertos de Estados Unidos debido a los controles por el coronavirus (15/05/2020).
} 
ción expuesta al Covid-19, ${ }^{21}$ la que está inmersa en una psicosis social por la pandemia del coronavirus, y ha polarizado las opiniones acerca de ello. ${ }^{22}$

\section{METODOLOGÍA Y FUENTES DE INFORMACIÓN}

Con base en la información disponible en la web y diversas plataformas, aplicamos el método deductivo que es lo opuesto al método inductivo, pues mientras que el método deductivo procura ir de lo general a lo particular, el método inductivo procede de modo inverso: a partir de premisas particulares se procura alcanzar conclusiones generales (Hernández et al., 2014). En él (método deductivo), se parte de la observación de datos derivados de la Secretaría de Salud (con un corte de personas mayores entre cero años o más) y porcentajes, registro de los sucesos generales disponible en on line como hemos citados antes (al 20 de octubre) y con ellos realizamos un análisis deductivo de la información citada, tomando en cuenta la dimensión demográfica y las comorbilidades, con base en ella, formular premisas generales apoyado con el enfoque de la vulnerabilidad del sistema demográfico. En la dimensión de consecuencias sociales, se aplicó el mismo criterio, pero apoyándose en datos del INEGI, CONAPO, CONEVAL, entre otros, para derivar con ello premisas macro y las consecuencias sociales del Covid-19 en nuestro país.

Lo anterior, se apoyó técnicamente con el cruce de variables rezagadas con el Covid-19 y los datos acumulados de marzo al 20 de octubre de 2020 (86,537 fallecimientos y 860,707 sobrevivientes al Covid-19). Pero hoy, la vulnerabilidad demográfica no podría entenderse sin el uso de la tecnología. Al tener un mundo de información generada por una diversidad de comunidades que ofrecen información acerca del Covid-19, revisamos de manera cotidiana en la red de información del Internet en tiempo real. Es decir, las tasas o modelos que usamos en este trabajo se apoyan en la metodología de la Netnografía, la cual es un método de investigación en Internet. Porque Internet es un indiscutible filón de generación de riqueza de información que se ha utilizado convenientemente dado su carácter evolutivo y de adaptación a las propuestas innovadoras de investigación. Por ello, la Netnografía es valorada, hoy por hoy, fundamentalmente, por

${ }^{21}$ Véase en "México, entre los 10 países con más contagios de Covid-19 en el mundo", consultado en https://www.marca.com/claro-mx/trending/2020/05/16/5ebf52b7ca4741f8708b462d.html $(25 / 09 / 2020)$.

22 INFOBAE, 2020, El coronavirus en México no avanza igual que en España e Italia: una gráfica lo demuestra, consultado en https://www.infobae.com/america/mexico/2020/03/18/ el-coronavirus-en-mexico-no-avanza-igual-que-en-espana-e-italia-una-grafica-lo-demuestra/?fbclid=IwAR1E68ZBrIGEWG6GOxpr-vWSMaUxGC3AIMS8ZKSBjf589Gvt0PK-xL1SBUY $(18 / 06 / 2020)$. 
las empresas para rastrear, permanentemente, foros, chats, grupos de noticias... lo que piensan los usuarios sobre temas tan dispares como ocio, salud, coches, viajes, juegos, formación estadística... y poder "medir", "juzgar" y "valorar" sus opiniones y actitudes hacia determinados productos o servicios (Aparici, 2010).

A la vez, a través de Internet podemos acceder a la información disponible en plataformas como la de la Universidad Johns Hopkins y dar seguimiento a la evolución global y por país del Covid-19. ${ }^{23}$ Asimismo podemos disponer de la cartografía o distribución espacial de la pandemia de las características sociodemográficas en la plataforma de dicha universidad. Para el caso de México, la Secretaría de Salud dispone de la base de datos, cuadros y gráficas de la evolución cotidiana del Covid-19 en nuestro país. ${ }^{24}$ Con ello podemos derivar un análisis, pero a la vez nos apoyamos en periódicos virtuales o en línea, revistas, libros y resultados de investigación, todos ellos disponible en línea. Todo esto en tiempo real entre lo virtual y la realidad. Pero como todo, también hay limitaciones, es decir, no se puede captar todo en tiempo real: por ejemplo, la fecundidad derivada del Covid-19 y otros temas demográficos y socioeconómicos cuyas variables usadas en este trabajo se suponen constantes.

\section{El sistema demográfico en riego por Covid-19 en México}

Livi Bacci (1993), en su obra "Introducción a la demografía", sostiene que la Demografía como ciencia estudia los componentes de la reproducción del sistema demográfico: los nacimientos, las muertes y las entradas y salidas por migraciones. A este "núcleo" teórico básico le llama ecuación compensadora y añade que la investigación demográfica es muy diversa sobre los respectivos determinantes, a la vez incluye la composición por edades (y las pautas de cada uno de los tres fenómenos en cada una de tales edades), pero también agrega otros comportamientos y características sociodemográficas. La nupcialidad, la salud, la anticoncepción, la regulación legal del aborto, las estructuras familiares y convivenciales, las políticas públicas sobre vivienda o el tratamiento fiscal a las familias son algunos ejemplos de temas que la demografía puede considerar importantes, precisamente porque influyen sobre su tema nuclear: la reproducción de la población global o local. Sin la pretensión de extendernos en una explica-

23 Johns Hopkins, Coronavirus Resourse Center, 2020, consultado en https://coronavirus.jhu. edu/?utm_source $=$ jhu_properties\&utm_medium $=$ dig_link\&utm_content $=$ ow_jhuhomepage\&utm_campaign=jh20 $(22 / 09 / 2020)$.

24 Secretaría de Salud, 2020, Información general sobre el nuevo coronavirus, Covid-19, consultado en https://www.gob.mx/salud (20/10/2020). 
ción demográfica, la crisis en la salud de la población, la Demografía como disciplina científica permitirá exponer algunas preocupaciones e hipótesis acerca de la pandemia que nos aqueja al día de hoy.

Por ejemplo, con la aparición del coronavirus algunos expertos plantearon modelos matemáticos como parte de las estrategias de lucha contra el Covid-19 en muchos países del mundo. ${ }^{25}$ Por ejemplo, había quienes sostenían que el Covid-19 infectaría a 70 por ciento de la población mundial y duraría dos años, ${ }^{26}$ a la vez, se sostenía que en América Latina la pandemia de Covid-19 avanzaba de manera preocupante en la región y en México. López Gatell (Secretario de Salud en México) sostenía que tendría una duración de tres años.

El 6 de marzo de 2020, se sostenía que la pandemia del coronavirus se seguía expandiendo por el mundo. Las alarmas de la Organización Mundial de la Salud estaban en su máximo nivel. Los casos totales del Covid-19 ascendían a 95,333 en todo el planeta. Las proyecciones eran que los infectados aumentarían rápidamente. El país más afectado siguió siendo China. Del total de infectados, 80,565 pertenecían al país asiático y 14,768 al resto del mundo. Lo más alarmante era que en las últimas 24 horas se habían registrado 2,241 casos adicionales, de los cuales 143 habían sido en China y 2,098 en otros países. El Covid-19 había causado 3,015 muertes en China y 267 fuera de la nación asiática. En Europa, el país más afectado era Italia, mientras que Bosnia y Herzegovina, Hungría, Eslovenia y Palestina reportaron nuevos casos de coronavirus. Los países más afectados, aparte de China, eran Corea del Sur $(5,766$ casos), Italia $(3,089)$, Irán $(2,922)$ y Japón (317). En Estados Unidos se registraron las primeras personas infectadas. En Latinoamérica llegó a Argentina, Brasil, Chile, Ecuador y México. Tedros Adhanom Ghebreyesus, director de la OMS, reconoció que estaba "profundamente preocupado" por el incremento de países con casos del Covid-19. ${ }^{27}$ Aunque al 5 de octubre de 2020, la OMS sostenía que diez por ciento de la población mundial ya se había infectado de Covid-19 y obviamente eso podía variar de un país a otro. ${ }^{28}$

\footnotetext{
${ }^{25}$ Fernando Paul, 2020, Coronavirus: los problemas con los modelos matemáticos que están detrás de las estrategias de lucha contra el covid-19 en muchos países, consultado en https://www. bbc.com/mundo/noticias-52093856 (07/07/2020).

${ }^{26}$ Excelsior, 2020, 'Covid-19 infectará al 70\% de la población mundial y duraría 2 años', consultado en https://www.excelsior.com.mx/global/covid-19-infectara-al-70-de-la-poblacion-mundial-y-duraria-2-anos/1370239 (24/05/2020).

${ }^{27}$ Francisco Ríos, Incontrolable la propagación del Covid-19 por el mundo, consultado en https://www.cambio16.com/covid-19-se-propaga-por-el-mundo-de-manera-incontrolable/ $(06 / 04 / 2020)$.

${ }^{28}$ Véase en "El 10 por ciento de la población mundial ya se infectó de covid-19: OM", consultado en https://www.msn.com/es-mx/noticias/mundo/el-10-de-la-poblaci\%C3\%B3n-mundial-yase-infect $\%$ C3\%B3-de-covid-19-oms/ar-BB19IwZt?ocid=msedgdhp (05/10/2020). Para otros,
} 
Para el caso de México, el Instituto Nacional de Salud Pública creó un tablero de monitoreo de epidemia SARS-CoV-2 para el seguimiento del Covid-19, en la cual se podía dar seguimiento de la distribución geográfica de la relación de positividad según entidad federativa (en donde permanentemente la Ciudad de México y el Estado de México ocuparon el primero y segundo lugar, respectivamente), la curva epidemiológica, los resultados por grupo etario y sexo (con mayor incidencia en varones en relación a la de las mujeres), así como de las defunciones por grupo etario (destacando las personas adultas mayores y el de los cuarenta años de edad) y sexo (lo mismo con mayor riesgo de contagio recayó sobre los hombres). ${ }^{29}$

Algunos medios difundían cifras escalofriantes, así se reconocían las proyecciones de infectados en Estados Unidos, a la vez que se reconocía una sub-enumeración en todo el mundo, el caso de China es emblemático debido a que la cifra de muertes por coronavirus en Wuhan fue 50 por ciento más de lo informado. ${ }^{30}$ Para el caso de México se decía que la cifra era de 56 mil mexicanos contagiados por el Covid-19, el 17 de abril de 2020 y cuya letalidad era de 0.87 por ciento según el Modelo Centinela de la Secretaría de Salud, ${ }^{31}$ aunque su múltiplo siempre apuntaba al doble.

Las cifras aquí citadas ameritan una discusión y reflexión mayor, sin embargo, el objetivo es revisar que se ha dicho en torno a la vulnerabilidad del sistema demográfico y social, lo cual se hará en los siguientes párrafos.

\section{La FeCUNDidad EN El CONTEXTo del Covid-19}

La fecundidad es un determinante de sistema demográfico y el Covid-19 tiene su efecto sobre este determinante. El número de hijos por mujer presenta una doble realidad en el mundo: un mundo occidental envejecido y un continente africano con elevada fecundidad; lo mismo que para algunos países de América Latina entre ellos México. Los países con ingresos altos, en general, tenían 1.6 hijos por mujer en 2018 mientras que en 1960 era de tres. En tanto que, en 2018, el número de hijos por mujer en países de bajos ingresos era de 4.6, por su parte, México se ubica como país de ingreso

decían que los casos de Covid-19 superan los 35 millones en el mundo, consultado en https:// www.eluniversal.com.mx/mundo/casos-de-covid-19-superan-los-35-millones-en-el-mundo $(05 / 10 / 2020)$.

29 INSP, 2020, Tablero interactivo sobre Covid-19, consultado en https://www.insp.mx/informacion-institucional-covid-19.html (10/10/2020).

30 El Financiero, 2020, China admite: cifra de muertes por coronavirus en Wuhan fue $50 \%$ más de lo informado, consultado en https://www.elfinanciero.com.mx/mundo/china-eleva-en-un-50el-numero-de-muertes-por-coronavirus-en-wuhan/ (28/04/2020).

31 Laura Poy Solano, 2020, La Ssa estima en 56 mil la cifra de mexicanos contagiados, consultado en https://www.jornada.com.mx/2020/04/17/politica/002n2pol (25/05/2020). 
medio con 2.1 hijos por mujer (Tabla 1). Sin embargo, estas cifras podrían cambiar y expresar la vulnerabilidad debido al Covid-19.

Tabla 1: Número de hijos por mujer según país y nivel de ingreso 1960-2018

\begin{tabular}{lcc}
\hline Países según ingresos & 1960 & 2018 \\
\hline Ingresos altos & 3.021 & 1.600 \\
Ingreso mediano & 5.627 & 2.335 \\
Ingreso mediano alto & 5.375 & 1.897 \\
Ingreso mediano bajo & 5.690 & 2.554 \\
Ingreso bajo & 6.582 & 4.604 \\
\hline
\end{tabular}

Fuente: Banco Mundial, disponible en https://datos.bancomundial.org/indicator/SP.DYN.CBRT.IN

Expertos del área de la Demografía consideran que la Covid-19 marcará más a la fecundidad que a la mortalidad, sobre todo porque esta crisis ha puesto una barrera a la inmigración (inmovilidad), que ayudaba a que las cifras no fueran todavía más negativas en países desarrollados. El proceso de envejecimiento se acelerará.

La natalidad se va a resentir en dichos países. Las parejas no tienen hijos por cuatro razones: la primera es que son demasiado jóvenes (o posponen el matrimonio por estudio o que es una generación que tiene otros objetivos) y todavía no entra en sus planes la reproducción. La segunda que ya no son tan jóvenes y tienen pareja. La tercera es que ahora que tienen pareja, no tienen los medios: empleo, hogar, cosas materiales que arreglar con dinero y la cuarta: lo tiene todo, pero con 38 o 40 años se entra con el problema para concebir. ${ }^{32}$

Esta es una primera expresión de vulnerabilidad del sistema demográfico y a ello le agregamos el tema de la crisis de salud debido a la pandemia del Covid-19.

Uno de los demógrafos prominentes de América Latina, José Miguel Guzmán, coordinador Regional del Programa de Encuestas Demográficas y de Salud en América Latina y África Francófona, en ocasión al Día Panamericano de la Estadística, sostiene que el acceso limitado a anticonceptivos y las medidas de confinamiento social para evitar la propagación del Covid-19, pudiera generar, además, dos distintos efectos en la fecundidad: reducción del potencial crecimiento poblacional en algunos países y, en

\footnotetext{
32 Véase en Albert Esteve, CED: Covid-19 marcará más la natalidad que la mortalidad, disponible en https://www.cambio16.com/albert-esteve-ced-covid-19-marcara-mas-la-natalidad-que-la-mortalidad/ (29/07/2020).
} 
otros, un aumento de embarazos no deseados. ${ }^{33}$ Pero a la vez, podría agravar la desigualdad de género de nuestros países y hogares.

Algunos demógrafos mexicanos han vaticinado apresuradamente la posibilidad de un incremento de los nacimientos fruto de una etapa de confinamiento prolongado. Pero, por otro lado, tendremos una acentuación de la caída derivada de las difíciles condiciones económicas a las que nos estamos viendo abocados por la pandemia.

Estos argumentos son afines a los planteados por la Comisión Económica para América Latina y el Caribe (CEPAL), la cual sostiene que el impacto en la tasa global de fecundidad por la pandemia:

podría observarse una disminución en función del impacto en las decisiones reproductivas y la postergación de la maternidad frente a la incertidumbre económica asociada a la crisis; pero todo dependerá del acceso a los servicios de salud sexual y reproductiva, en particular a los métodos anticonceptivos, y la duración de la crisis (CEPAL, 2020).

Sin embargo, aún con fluctuaciones, la tendencia hacia el descenso en los niveles de fecundidad que experimenta la región (América Latina), en principio no se vería afectada. En general, en tiempos de shocks, como fue el caso reciente de la epidemia de Zika en 2016 en Brasil (Castro et al., 2018 y Marteleto et al., 2020), el número de nacidos vivos disminuye en algún momento después del comienzo del brote, en general nueve meses, volviendo al nivel esperado más tarde. Esto fue registrado por Stone (2020) en otros momentos de brotes epidémicos y por Adsera y Menendez (2011) y Lee (1990) en momentos de crisis económicas. ${ }^{34}$

En México, el Consejo Nacional de Población (CONAPO) estimó que habrá 21 mil 575 embarazos adicionales en promedio de adolescentes durante la epidemia, al dejar de acudir a los servicios de salud sexual y reproductiva por temor a contraer Covid-19, y porque las niñas de entre 10 a 14 años son las más expuestas a sufrir violencia sexual por parte de un familiar o una persona cercana. ${ }^{35}$ Pero lo más inhumano son las cirugías no

\footnotetext{
33 En "Demógrafo advierte que el Covid-19 provocaría dos efectos distintos en la fecundidad", disponible en https://www.eldinero.com.do/106748/demografo-advierte-que-el-covid-19-provocaria-dos-efectos-distintos-en-la-fecundidad/ (30/07/2020).

${ }^{34}$ CEPAL, 2020, "Día Mundial de la Población 2020: Las huellas de la pandemia en las tendencias demográficas en la región", disponible en https:/www.cepal.org/es/notas/dia-mundial-la-poblacion-2020-huellas-la-pandemia-tendencias-demograficas-la-region (30/07/2020).

${ }_{35}$ CONAPO; 2020, "CONAPO estima 21 mil embarazos adicionales de adolescentes durante epidemia”, disponible en https://www.animalpolitico.com/2020/08/conapo-estimacion-embarazos-adolescentes/(04/08/2020).
} 
autorizadas a mujeres migrantes en Estados Unidos que sin duda influirá en su reproducción. ${ }^{36}$

La fecundidad se expresa de manera diferenciada ante Covid 19 y el Estado de México no es la excepción, sin duda dejará huella tanto en embarazos-confinamiento como en los nacimientos en el contexto de la crisis pandémica, ${ }^{37}$ lo cual es una expresión de la vulnerabilidad de las mujeres, principalmente.

\section{La mortalidad Por CaUSAS de Covid-19}

Las defunciones (es una determinante natural), en el análisis del sistema demográfico, permiten generar-probar hipótesis explicativas de que intentan mostrar las causas de la mortalidad o movimiento que genera huecos demográficos en la estructura de edad de una población a causa de guerras, pandemias, epidemias, desastres naturales, entre otros (o según sea el interés teórico del investigador). En términos de Livi Bacci (2012) es una de las almas del sistema demográfico o uno de los factores endógenos causantes de la salida de población. ${ }^{38}$ En términos de la teoría de la vulnerabilidad demográfica es la exposición al riesgo de fallecer, pero influenciado por la desigualdad en el ingreso, tal como podemos apreciar en la Tabla 2, es mayor la tasa de mortalidad infantil por distintas causas en los países de bajos ingresos y menor en aquellos con altos ingresos promedio entre 1990 y 2018 .

\footnotetext{
36 Véase en "Surgen más denuncias de migrantes con cirugías no autorizadas", consultado en https:/www.jornada.com.mx/sin-fronteras/2020/09/20/surgen-mas-denuncias-de-migrantes-con-cirugias-no-autorizadas-8371.html (21/09/2020) y, en "Investigarán reporte de histerectomías masivas a migrantes" consultado en https://www.jornada.com.mx/sin-fronteras/2020/09/16/ investigaran-reporte-de-histerectomias-masivas-a-migrantes-7449.html (21/09/2020).

37 Sobre este tema véase en Información social estatal y nacional Serie anual de 2000 a 2009 , consultado en http://igecem.edomex.gob.mx/sites/igecem.edomex.gob.mx/files/files/ArchivosPDF/Productos-Estadisticos/Indole-Economica/AGENDA-ESTADISTICA-BASICA/Agenda Estadistica Basica del Estado_de_Mexico_2010.pdf (30/11/2020).

${ }_{38}$ Introducción de la Demografía, disponib̄le en https://estvitalesydemografia.files.wordpress. com/2013/04/intropduccic3b3n-a-la-demografc3ada-livi-bacci-massimo.pdf (30/07/2020).
} 
Tabla 2: Tasa de mortalidad infantil en varones y mujeres por cada mil nacidos vivos

\begin{tabular}{lcrrr}
\hline País según ingreso & Varones (tasa) & \multicolumn{3}{c}{ Mujeres (tasa) } \\
& 1990 & 2018 & 1990 & 2018 \\
\hline Altos ingresos & 10.4 & 4.3 & 9.2 & 7.5 \\
Ingreso mediano & 69.2 & 29.5 & 61.9 & 25.5 \\
Ingreso mediano alto & 43.4 & 11.6 & 37.6 & 9.9 \\
Ingreso mediano bajo & 74.9 & 33.7 & 66.3 & 28.8 \\
Ingreso bajo & 117.8 & 52.5 & 102.2 & 43.4 \\
\hline
\end{tabular}

Fuente: Banco Mundial, disponible en https://datos.bancomundial.org/indicator/SP.DYN.IMRT. MA.IN

La mortalidad por Covid-19 ha aumentado en términos absolutos en el mundo. Se contabilizan a la fecha (30/07/2020) 17 millones de casos confirmados en el mundo. Tan solo en Estados Unidos se han confirmado más de 4.4 millones de casos de Covid-19, en Brasil se reportan más de 2.5 millones, en Perú más de 400 mil, en México más de 408 mil, en Chile más de 353 mil, en España más de 285 mil, en Colombia más de 276 mil y en Argentina más de 178 mil, al 30 de julio. El número de pacientes dados de alta también ha superado los nueve millones de personas. ${ }^{39}$

Más de 669 mil defunciones debido a la nueva enfermedad y $9.8 \mathrm{mi}-$ llones de recuperados. Aunque ese valor parezca bajo comparado con la estimación promedio anual, para el periodo 2015-2020, de 4.2 millones de muertes esperadas en 2020 (United Nations, 2019), al observar el exceso de defunciones totales contrastando las cifras de un mismo mes en 2019 y 2020, los valores son significativamente mayores y preocupantes (Lima et al., 2020). Los países con mayores defunciones son: Estados Unidos (151,451 personas fallecidas); Brasil con más de 90 mil; Reino Unido con más de 45 mil; México con 45,361, Italia con más de 35 mil, India con más de 34 mil, etcétera. ${ }^{40}$ Pero un datos más reciente apunta que Estados Unidos encabeza los fallecimientos por Covid-19, con 258,333, para Brasil 168,141, la India con 132 mil y México rebasando los 100 mil falleci-

\footnotetext{
39 Johns Hopkins, 2020, Covid-19 Dashboard by the Center for Systems Science and Engineering (CSSE) at Johns Hopkins University (JHU), consultado en https://coronavirus.jhu.edu/map. html (30/07/2020)

${ }_{40}$ Johns Hopkins, 2020, Covid-19 Dashboard by the Center for Systems Science and Engineering (CSSE) at Johns Hopkins University (JHU), consultado en https:/coronavirus.jhu.edu/map. html (30/07/2020)
} 
mientos y ocupando el lugar número cuatro a nivel mundial. ${ }^{41}$ Las cifras expresan vulnerabilidades diferenciadas que tendrán un efecto diferencial en cada sistema demográfico, pero ciertamente el sistema demográfico mundial tendrá la huella pandémica en su estructura.

El Covid 19 convirtió al año 2020 con más defunciones en la historia reciente de México aunque las entidades federativas presentan diferencias importantes. ${ }^{42}$ En términos de la exposición al contraer la enfermedad o fallecer recae en los mayores de edad, en hombres, hablantes de lengua indígena, migrantes, mayoritariamente de nacionalidad mexicana. Pero los de mayor exposición al fallecimiento son quienes tienen comorbilidades como la diabetes, Epoc (enfermedad pulmonar obstructiva crónica), asma, hipertensión, enfermedades cardiovasculares, obesidad, enfermedades renales crónicas y tabaquismo (véase Tabla 3). En este caso para el Estado de México, podemos apreciar, a manera de ejemplo, mayores posibilidades de la exposición al riesgo de padecer dicha enfermedad, incluso de fallecer, sobre todo, si las personas presentan comorbilidades y esto significa una mayor vulnerabilidad y poca capacidad de respuesta ante la pandemia.

En nuestro país se sostiene que la mortalidad proyectada por entidad federativa es mayor en la Ciudad de México y en el Estado de México, así como de los observados derivados de la pandemia del Covid-19. ${ }^{43}$ Por ejemplo, el valor esperado de la mortalidad en el Estado de México era de 27,502 y el observado fue de 57,328 presentando un exceso de mortalidad de 29,899 (en la semana 31). ${ }^{44}$ Pero hasta el 20 de octubre podemos observar que la entidad mexiquense tenía un patrón de mayor afectación en lo demográfico y en sus comorbilidades en relación al nacional (Tabla 3).

\footnotetext{
41 Véase en "Se rompe techo de 100,000 muertos por Covid-19 en México", consultado en https://www.eleconomista.com.mx/politica/Se-rompe-techo-de-100000-muertos-por-Covid-19en-Mexico--20201120-0031.html (20/11/2020).

${ }_{42}$ Véase en https://www.gob.mx/salud (30/11/2020).

43 Véase en "Mapa del coronavirus en México; CdMx, entidad con mayor mortalidad", consultado en https://www.msn.com/es-mx/noticias/mexico/mapa-del-coronavirus-en-m\%C3\%A9xicocdmx-entidad-con-mayor-mortalidad/ar-BB1aXZQv?ocid=msedgdhp (13/11/2020).

44 Véase en "Estado de México. Exceso de mortalidad por todas las causas, Semana 31, 2020", consultado en https:/www.insp.mx/micrositio-covid-19/boletin-estadistico-sobre-exceso-demortalidad-por-todas-las-causas-durante-la-emergencia-por-covid-19 (18/09/2020). Los mismo se puede consultar en "Boletín ESTADÍSTICO sobre el exceso de mortalidad por todas las causas durante la emergencia por Covid-19", consultado en https:/coronavirus.gob.mx/wpcontent/uploads/2020/10/BoletinIV_ExcesoMortalidad_SE39MX21102020.pdf?fbclid=IwAR3 V2O5XYMKrufv1ZjnOPT9rdNLrpYQJP2bIIfdqdsRj-JAV18RqtYtnFOA (11/11/2020).
} 
Tabla 3: Porcentaje de sobrevivientes y fallecimientos por Covid-19 de la población de 0 años o más, según causa (al 20 de octubre de 2020).

Datos Demográficos

\begin{tabular}{|c|c|c|c|c|}
\hline & \multicolumn{2}{|c|}{ Nacional } & \multicolumn{2}{|c|}{ Estado de México } \\
\hline & $\begin{array}{r}\text { Sobrevive } \\
(\%)\end{array}$ & $\begin{array}{r}\text { Falleció } \\
(\%)\end{array}$ & $\begin{array}{r}\text { Sobrevive } \\
(\%)\end{array}$ & $\begin{array}{r}\text { Falleció } \\
(\%)\end{array}$ \\
\hline \multicolumn{5}{|l|}{ Edad } \\
\hline 0 a 14 años & 98.6 & 1.4 & 97.8 & 2.2 \\
\hline 15 a 29 años & 99.3 & 0.7 & 98.3 & 1.7 \\
\hline 30 a 49 años & 96.3 & 3.7 & 93.8 & 6.2 \\
\hline 50 a 69 años & 82.4 & 17.6 & 76.1 & 23.9 \\
\hline 70 a 120 años & 60.2 & 39.8 & 54.4 & 45.6 \\
\hline Total & 89.9 & 10.1 & 85.6 & 14.4 \\
\hline \multicolumn{5}{|l|}{ Sexo } \\
\hline Mujer & 92.6 & 7.4 & 89.9 & 10.1 \\
\hline Hombre & 87.5 & 12.5 & 81.8 & 18.2 \\
\hline Total & 89.9 & 10.1 & 85.6 & 14.4 \\
\hline \multicolumn{5}{|l|}{$\begin{array}{l}\text { Habla lengua } \\
\text { indígena }\end{array}$} \\
\hline No & 89.9 & 10.1 & 85.6 & 14.4 \\
\hline Sí & 83.1 & 16.9 & 76.2 & 23.8 \\
\hline Total & 89.8 & 10.2 & 85.5 & 14.5 \\
\hline \multicolumn{5}{|l|}{ Migrante } \\
\hline No & 96.4 & 3.6 & 97.4 & 2.6 \\
\hline Sí & 94.2 & 5.8 & 94.7 & 5.3 \\
\hline Total & 95.9 & 4.1 & 96.8 & 3.2 \\
\hline \multicolumn{5}{|l|}{ Nacionalidad } \\
\hline Mexicana & 89.0 & 10.1 & 85.6 & 14.4 \\
\hline Extranjera & 95.5 & 4.5 & 97.3 & 2.7 \\
\hline Total & 89.9 & 10.1 & 85.6 & 14.4 \\
\hline \multicolumn{5}{|l|}{ Embarazo } \\
\hline No & 92.4 & 7.6 & 89.7 & 10.3 \\
\hline Sí & 98.6 & 1.4 & 98.5 & 1.5 \\
\hline Total & 92.5 & 7.5 & 89.7 & 10.3 \\
\hline
\end{tabular}


Los riesgos de la vulnerabilidad sociodemográfica por el Covid-19 en México 2020 / J.G. GONZÁLEZ y B.J. MONTOYA

\section{Migración y Covid-19}

Antes de la pandemia estábamos acostumbrados a definir a la migración interna ${ }^{45}$ e internacional (al inicio se ocupa el concepto del Covid-19 importado, debido a la movilidad internacional) como cambio de residencia habitual por situaciones económicas, políticas, sociales, ambientales y tecnológicas. Y, estábamos discutiendo la emigración, la inmigración, el retorno y la migración en tránsito. Pero a partir de marzo de 2020, entra un concepto que algunos científicos sociales han llamado inmovilidad relacionado con la migración interna e internacional (que incluye las repatriaciones), ${ }^{46}$ esto a causa de la pandemia del Covid-19.

La migración interna rural-urbana (y a la inversa) y la urbana temporal, cotidiana y pendular tuvieron un periodo de inmovilidad por el Covid-19, todos ellos basaban sus movimientos para el empleo formal e informal, estudio, consultas médicas, compras entre otras actividades, principalmente entre zonas metropolitanas. ${ }^{47}$ Basta mirar que los porcentajes de fallecimientos y sobrevivientes por Covid-19 están concentrados en las regiones del norte, el centro y sur de país (Tabla 4).

\footnotetext{
45 "La migración interna es un componente decisivo del sistema demográfico y de los procesos de redistribución espacial de la población y tiene implicaciones para comunidades, hogares y personas. Para las comunidades, en particular las de origen y las de destino, tiene efectos demográficos -tanto en materia de crecimiento como de estructuras de la población, sociales, culturales y económicas. Para los hogares y las personas, la migración, en particular sì se enmarca en una estrategia elaborada, es un recurso para el logro de determinados objetivos, los que pueden ser tan variados como enfrentar una crisis económica o mejorar la calidad de vida.", en Migración interna y distribución espacial de la población, disponible en https://biblioguias.cepal.org/ migracioninterna $(31 / 07 / 2020)$.

46 Véase en "Ebrard: 17 mil 891 mexicanos han sido repatriados ante crisis por coronavirus", consultado en https:/www.milenio.com/politica/coronavirus-sre-17-mil-891-mexicanosrepatriados $(21 / 10 / 2020)$.

47 Virgilio Partida-Bush, 2013, Migración hacia y desde 16 zonas metropolitanas de México. Una reconstrucción histórica 1965-2010, disponible en http://www.scielo.org.mx/scielo.php?script $=$ Sci arttext\&pid=S1405-74252013000200002 (03/08/2020); también en Carlos Garrocho, 2011, Pob̄lación Flotante, Población en Movimiento: Conceptos Clave y Métodos de Análisis Exitosos, disponible en https:/www.gob.mx/cms/uploads/attachment/file/328284/Poblaci_n flotante GarrochoISBN.pdf (03/08/2020); y, en José Aurelio Granados-Alcantar, Laura Myriam Franco-Sánchez, 2017, Migración y movilidad laboral entre las zonas metropolitanas de la región centro de México, disponible en http://www.scielo.org.mx/scielo.php?script=sci_arttext\&pid=S1405-74252017000100117 (03/08/2020).
} 
Tabla 4: Porcentaje de sobrevivientes y fallecimientos por Covid-19 de la población de 0 años o más, según causa (al 20 de octubre de 2020). Enfermedades crónico-degenerativas

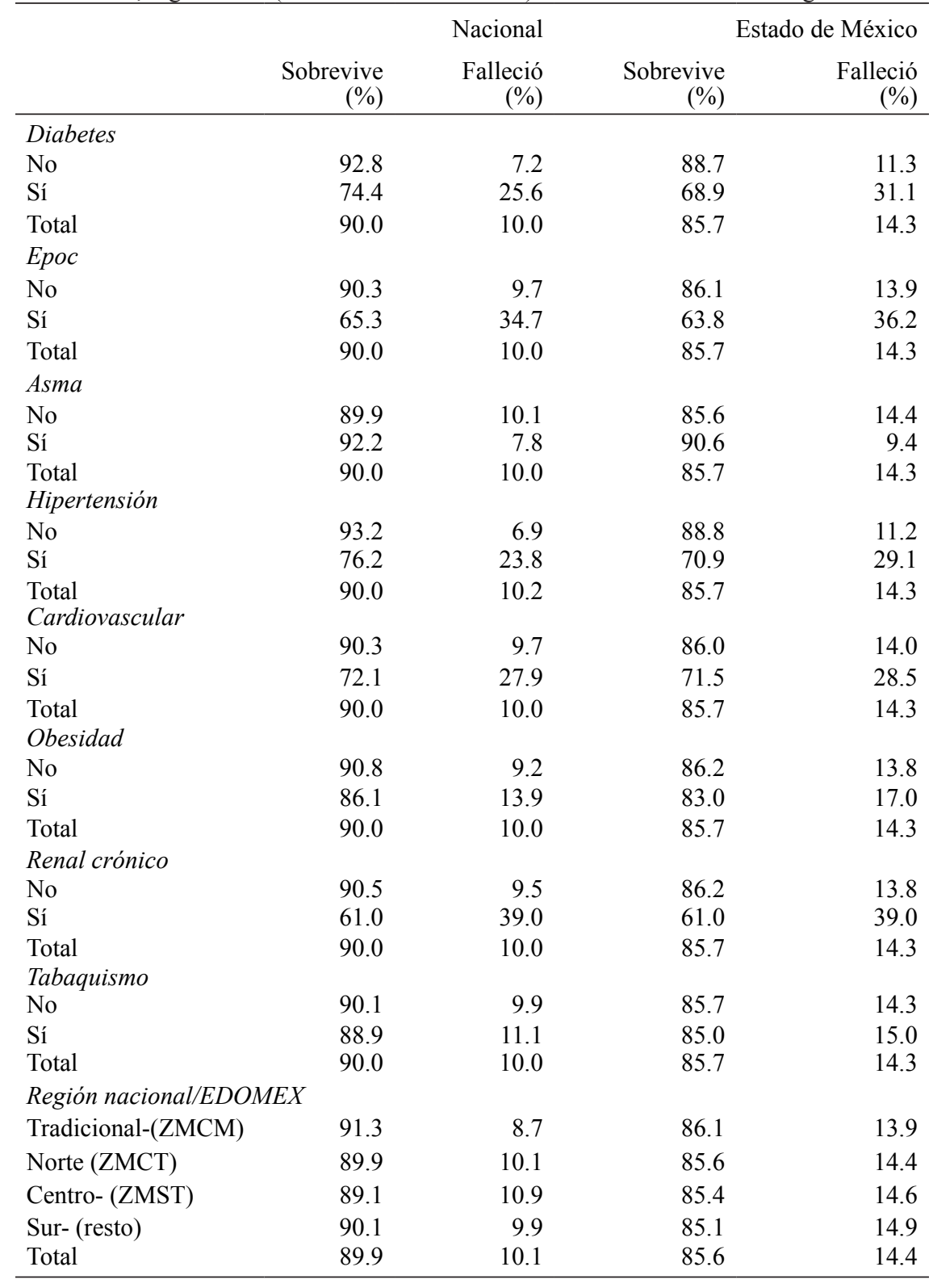

Nota: ZMCM = Zona Metropolitana de la Ciudad de México; ZMCT = Zona Metropolitana de la Ciudad de Toluca; ZMST = Zona Metropolitana Santiago Tianguistenco; resto (resto de los municipios no metropolitanos).

Fuente: elaboración propia con base en https://coronavirus.gob.mx/ 
Asimismo, por la pandemia del Covid-19 se agravan las condiciones económicas y sociales de sectores que ya eran altamente vulnerables, como los niños, niñas y adolescentes migrantes (NNA, internos e internacionales), jornaleros agrícolas, migrantes en retorno y en busca de refugio, así como trabajadores indocumentados en Estados Unidos (como los de tránsito). Esto se argumentó en el seminario virtual "Migración y desigualdades ante Covid-19: poblaciones vulnerables y redes de apoyo en México y Estados Unidos", evento organizado por El Colegio de México. ${ }^{48}$ Esto tuvo implicaciones en el alma biológica-social de la población al someterla a la inmovilidad.

El Covid-19 arremete entonces en un espacio geográfico de antemano marcado por la tensión entre (in)movilidad y control, tensión que toma matices mucho más violentos en contextos desiguales. Ese es el caso de las Américas. En las últimas décadas la desigualdad socioeconómica, entre los países del continente y al interior de los mismos, se ha profundizado sin precedentes históricos. De ahí que, en solo dos meses, la pandemia haya desnudado la desatendida e irresuelta desigualdad estructural, desatando consecuentemente considerables afectaciones en nuestros países. A la emergencia sanitaria hoy se suma el colapso económico y el de los sistemas de protección social, hechos que en conjunto asuelan las vidas de las poblaciones más vulnerabilizadas, siempre racializadas, como aquellas en condición de movilidad humana. ${ }^{49}$

La inmovilización lleva implícito elementos como cierre de fronteras e hipervigilancia, hipernacionalismo selectivo, espiral de violencia, desposesión de derechos, derechos de asilo y refugio, producción de miedo, espacios de confinamiento, migración en reversa, esenciales, pero desechables, niñez y adolescentes al borde de la crisis humanitaria y México también aplicó dichas medidas ${ }^{50}$ con el despliegue de la guardia nacional que a la vez fue reconocido como el muro contra la migración a Estados Unidos. De hecho, en México había 100 mil migrantes en riesgo por Covid-19 el día 01 de julio del 2020, alertaba la Universidad Nacional Autónoma de México (UNAM). ${ }^{51}$

\footnotetext{
${ }^{48}$ Agrava Covid-19 condiciones de sectores vulnerables: Colmex, disponible en https://migdep.colmex.mx/publicaciones/COVID-19-Contexto-Economico-Politico-Social.pdf?fbclid=IwAR2xy_UQvUIoHKcvBGWQIVhKZLaND0S_2Sx2RqIOkUCVwaAaz5vcJK8qwxo $(01 / 08 / 2020)$.

${ }_{49}$ Covid-19 E (IN)MOVILIDAD EN LAS AMÉRICAS, disponible en https://www.inmovilidadamericas.org/el-proyecto (31/07/2020).

${ }_{50}$ MÉXICO, disponible en https://www.inmovilidadamericas.org/mexico (31/07/2020).

${ }^{51}$ Véase en https://www.jornada.com.mx/ultimas/sociedad/2020/07/01/en-mexico-hay-100mil-migrantes-en-riesgo-por-covid-19-alerta-la-unam-4683.html (31/07/2020).
} 
Pero también, ha habido fallecimientos de migrantes, sobre todo mexicanos y los más numerosos justamente fueron en el epicentro de la pandemia de Estados Unidos: Nueva York, California, Illinois, Arizona, Texas, Wisconsin, Nueva Jersey, Carolina del Norte, Maryland, Minnesota, Colorado, Washington entre otros, tal como lo expresan la Tabla 5 y la Figura 1.

Tabla 5: Fallecimientos de mexicanos y mexicanas por Covid-19 en Estados Unidos

\begin{tabular}{lrrlrr}
\hline Estado & $\begin{array}{r}\text { Personas } \\
\text { mexicanas }\end{array}$ & $\begin{array}{r}\text { Totales } \\
\text { estatales }\end{array}$ & Estado & $\begin{array}{r}\text { Personas } \\
\text { mexicanas }\end{array}$ & $\begin{array}{r}\text { Totales } \\
\text { estatales }\end{array}$ \\
\hline Alabama & 2 & 1,291 & Michigan & 13 & 6,366 \\
Arizona & 79 & 2,784 & Minnesota & 28 & 1,585 \\
Arkansas & 1 & 357 & Mississippi & 4 & 1,358 \\
California & 289 & 7,716 & Missouri & 3 & 1,165 \\
Carolina del Norte & 32 & 1,667 & Nebraska & 11 & 301 \\
Carolina del Sur & 3 & 1,164 & Nevada & 7 & 647 \\
Colorado & 27 & 1,752 & Nueva Jersey & 34 & 15787 \\
Dakota del Sur & 1 & 118 & Nuevo México & 2 & 571 \\
Delaware & 2 & 523 & Nueva York* & 760 & 32,582 \\
Distrito de Columbia & 7 & 579 & Ohio & 3 & 3,189 \\
Florida & 12 & 5,075 & Oklahoma & 4 & 452 \\
Georgia & 19 & 3,173 & Oregón & 7 & 260 \\
Idaho & 0 & 119 & Pensilvania & 20 & 7,085 \\
Illinois & 160 & 7,488 & Rhode Island & 1 & 995 \\
Indiana & 17 & 2,825 & Tennessee & 7 & 843 \\
Iowa & 5 & 977 & Texas & 60 & 4,063 \\
Kansas & 6 & 308 & Utah & 14 & 243 \\
Kentucky & 5 & 670 & Virginia & 14 & 2,031 \\
Luisiana & 3 & 3,576 & Washington & 25 & 1,454 \\
Maryland & 30 & 3,380 Wisconsin & 56 & 1,454 \\
Massachusetts & 7 & 8,431 & Totales & 1,780 & 135,616 \\
\hline Data 20 & & & & &
\end{tabular}

Datos al 20 de julio.

*Incluye Connecticut y condados de Nueva Jersey.

Fuente: Secretaría de Relaciones Exteriores, 2020, disponible en https://www.gob.mx/sre/documentos/nota-informativa-relaciones-exteriores-no-31?idiom=es (01/08/2020). 
Los riesgos de la vulnerabilidad sociodemográfica por el Covid-19 en México 2020 / J.G. GONZÁLEZ y B.J. MONTOYA
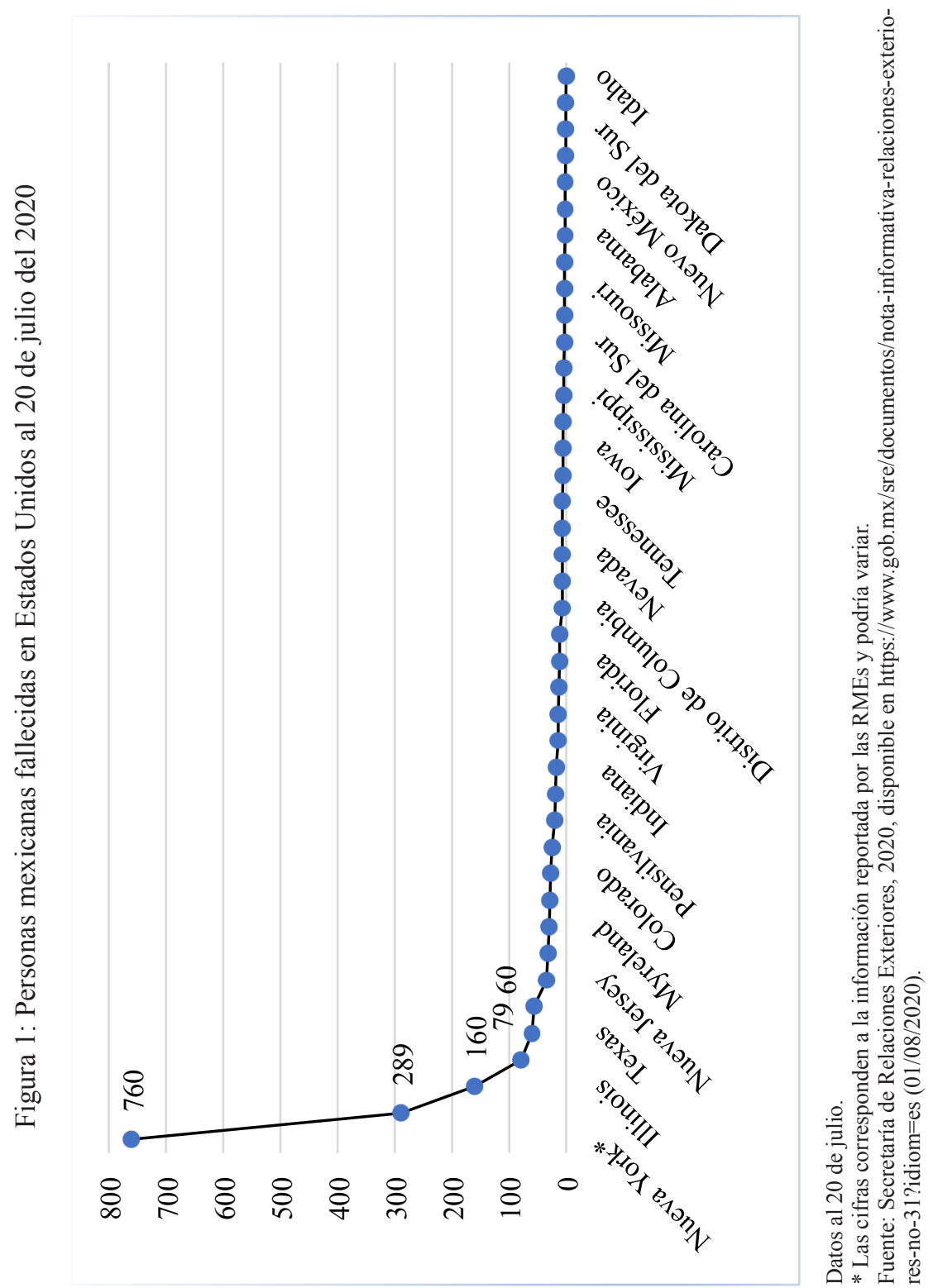
Los datos así presentados esconden particularidades, tales como el de la inmovilidad estudiantil internacional ${ }^{52}$ y el Covid-19, así como de jornaleros, mujeres, etcétera.

Entre los mexicanos (as), fallecidos en otros países del mundo destacan los sucedidos en Canadá, España y Perú (Tabla 6).

Tabla 6: Fallecimientos de mexicanos y mexicanas por Covid-19 en el resto del mundo

\begin{tabular}{lrr}
\hline País & Personas mexicanas (os) & Totales en el país \\
\hline Canadá & 6 & 8,855 \\
Colombia & 1 & 6,736 \\
Cuba & 0 & 87 \\
Chile & 0 & 8,633 \\
España & 3 & 28,420 \\
Francia & 1 & 31,017 \\
Irlanda & 0 & 1,753 \\
Italia & 0 & 35,058 \\
Kenia & 0 & 238 \\
Panamá & 0 & 1,096 \\
Perú & 3 & 13,187 \\
Portugal & 0 & 1,691 \\
República Dominicana & 0 & 993 \\
Suiza & 0 & 1,971 \\
Tailandia & 0 & 58 \\
Totales & 14 & 139,793 \\
\hline
\end{tabular}

Fuente: Secretaría de Relaciones Exteriores, 2020, disponible en https://www.gob.mx/sre/documentos/nota-informativa-relaciones-exteriores-no-31?idiom=es $(01 / 08 / 2020)$. Para las actualizaciones véase en https://www.gob.mx/sre/documentos/nota-informativa-relaciones-exteriores-no-35?idiom=es y en https://www.gob.mx/sre/documentos/nota-informativa-relaciones-exteriores-no-48?idiom=es (consultados el 13/11/2020).

Los migrantes fueron en un inicio sujetos de la importación del Covid, 19, pero a la vez, se han convertido en una bomba de tiempo en centros de detención de migrantes en las fronteras internacionales, los cuales han obligado a suspender las leyes de inmigración y se refuerza la imagen de una frontera cerrada por la pandemia.

52 Véase en "Movilidad estudiantil internacional", consultado en https://www.jornada.com. mx/2020/11/20/opinion/024a2pol (20/11/2020). 
El perfil demográfico de los fallecidos en el mundo indica que el mayor porcentaje se concentra en las edades de 50 o más años de edad y, mayoritariamente masculina. Obviamente con grandes diferencias entre países de mayor y menor desarrollo. ${ }^{53}$

En nuestro país, expertos de la Universidad Nacional Autónoma de México (UNAM) apuntan a la existencia de un perfil de mortalidad asociado a algunas condiciones demográficas y socioeconómicas: Menor escolaridad, 70 por ciento son hombres y más de la mitad (55.7 por ciento) se concentran en la Ciudad de México y en el Estado de México. Uno de cada dos decesos son adultos mayores y 45 por ciento corresponde a la clase trabajadora; casi 84 por ciento de los muertos por el nuevo coronavirus se concentra en ocho categorías de empleo, entre los que destacan los no remunerados como las amas de casa, jubilados y pensionados, empleados de sector público, conductores de vehículos y profesionales no ocupados. En especial, ha llamado la atención la vulnerabilidad de aquellos que no desempeñan un empleo activo - no remunerados, jubilados y pensionados, y no ocupados- que en conjunto suman 46 por ciento de las defunciones, así como de aquellos que padecen alguna enfermedad crónico degenerativa. ${ }^{54}$

En síntesis, las consecuencias sociodemográficas de la pandemia serán reflejadas en la ecuación compensadora de la población: por ejemplo, los huecos demográficos que dejará en la estructura de edad por la mortalidad (cuyo diferencial por habitante puede variar entre un país y otro en el tiempo), ${ }^{55}$ en su esperanza de vida al nacer, en la población masculina y, en menor medida, en el caso de las mujeres jóvenes ${ }^{56}$ y niños. Aumento o disminución de la fecundidad según país o entidad federativa por el efecto de la menor tasa de matrimonios y del confinamiento.

Pasar de la movilidad a la inmovilidad y, luego, nuevamente a la movilidad con mayor proteccionismo de los países desarrollados, expone al

53 ¿A qué edad se está muriendo por coronavirus en el mundo?, consultado en https://www. elconfidencial.com/tecnologia/ciencia/2020-03-12/covid-coronavirus-edad-muriendo-mundo $2493175 /(02 / 08 / 2020)$. Asimismo, en "El impacto de la pandemia por Covid-19 en las personas mayores", https://www.cepal.org/es/notas/impacto-la-pandemia-covid-19-personas-mayores (02/08/2020). También en América Latina: Retos y oportunidades", consultado en https:// scielo.conicyt.cl/scielo.php?script=sci arttext\&pid=S0370-41062020000200179 (02/08/2020).

${ }_{54}$ Véase en Estudio relaciona mortalidad del Covid-19 con la escolaridad, disponible en https://www.jornada.com.mx/ultimas/sociedad/2020/07/14/revelan-estudio-sobre-201 cmortalidad-por-covid-19-en-mexico201d-7844.html (30/07/2020).

${ }_{55}$ Véase en "El modelo Centinela, la apuesta de México para contener la epidemia de coronavirus (y que contradice las recomendaciones de la OMS)", consultado en https://actualidad.rt.com/ actualidad/348982-modelo-centinela-estrategia-mexico-coronavirus (04/09/2020).

${ }_{56}$ Véase en "Según datos de la Secretaría de Salud, el grupo etario más afectado por la enfermedad hasta el momento es el de los 40 a los 49 años" (México), consultado en https:// www.elsoldemexico.com.mx/mexico/sociedad/bajo-observacion-los-cuarentones-los-mas-afectados-por-el-covid-19-5123349.html (04/0/2020). 
riesgo a 7.5 mil millones de habitantes en riesgo al igual que $271.6 \mathrm{mi}-$ llones de migrantes en el mundo de los cuales 40 millones de mexicanos radicados en distintas partes del mundo y 12 millones nacidos en el país que viven en Estados Unidos, además de su segunda y tercera generación que se reconocen como mexicanos.

Las consecuencias en torno a la migración internacional son el aumento de la mortalidad en un lugar distinto al de su nacimiento, ${ }^{57}$ aumenta el costo y el tráfico de personas después de tres meses de inmovilidad (marzo, abril y mayo); ${ }^{58}$ aumenta el retorno a sus comunidades dada la incertidumbre en los lugares de destino; facilita la deportación: violación a sus derechos humanos en los países centrales, pero también desde México se hace una deportación diferencial; empeora la situación de refugiados y asilados: cuarentena en los campos de refugiados (que los pone en el limbo de las leyes migratorias vigentes), ${ }^{59}$ aumenta la discriminación, xenofobia y aporofobia (lo peor de todo cuando es institucionalizada como en Estados Unidos) en los lugares de tránsito y destino; ocurre un vaciamiento de las estaciones migratorias del Instituto Nacional de Migración (INAMI): motines en las estaciones de Chiapas, Tabasco, Sonora y Coahuila (el caso de México); miles de mexicanos varados en el exterior sin poder regresar a su país de origen; una mayor vulnerabilidad; según sexo (masculino), mayores de edad, enfermos crónicos-degenerativos; aumenta la migración forzada interna e internacional; ha ocurrido un freno al envío de remesas monetarias a nivel mundial y el caso de México al de cuatro mil millones en marzo del 2020 a 3.5 mil millones en julio de ese mismo año (Figura 2).

\footnotetext{
57 Véase en "Migrantes, entre las mayores víctimas del Covid-19 en EU", consultado en https://observatoriocolef.org/noticias/migrantes-entre-las-mayores-victimas-del-covid-19-eneu/?fbclid=IwAR07BTw8VUjJD0Cy1h_Id7tp4E7dmH1ZxVDgN5ed7TSpO_iOl1bBVuHiyE0 (04808/2020). Pero además hay una concentración de su deceso "Más de mil mexicanos han muerto en EU por Covid-19: Cancillería; en su reporte, la dependencia indicó que el mayor número de decesos de connacionales en ese país se concentra en Nueva York", consultado en https://www.elfinanciero.com.mx/mundo/mas-de-mil-mexicanos-han-muerto-en-eu-por-covid19-cancilleria (04/09/2020).

58 Véase en "La trata de personas, el negocio que resurge entre la pandemia y la crisis económica", consultado en https://www.jornada.com.mx/sin-fronteras/2020/09/04/la-trata-de-personas-elnegocio-que-resurge-entre-la-pandemia-y-la-crisis-economica-6740.html (07/09/2020).

59 En una rueda de prensa en Ginebra, Suiza, ACNUR alertó que una creciente situación de violencia e inseguridad crónicas, junto con restricciones relacionadas al covid-19, están poniendo en riesgo las vidas de decenas de miles de personas en el Norte de Centroamérica, al tiempo que exacerba las dificultades ya existentes, consultado en https:/www.proceso.com.mx/630264/ pandemia-agrava-crisis-migratoria-centroamericana-acnur (04/09/2020).
} 
Los riesgos de la vulnerabilidad sociodemográfica por el Covid-19 en México 2020 / J.G. GONZÁLEZ y B.J. MONTOYA

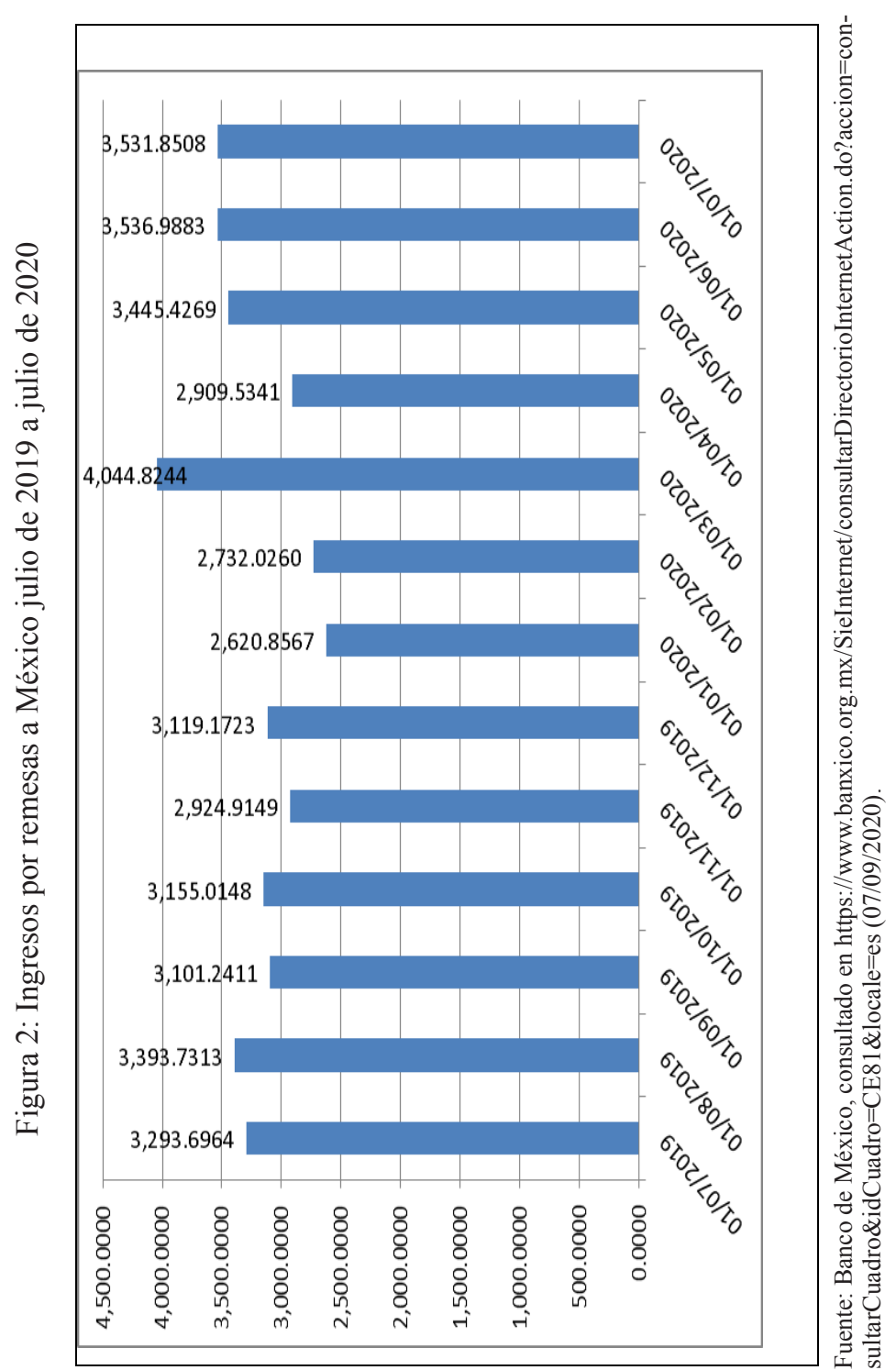


Pero se destaca el carácter del migrante solidario ${ }^{60} \mathrm{y}$ hoy llamadas benditas remesas o bendita migración que si no fueran por ellos estaríamos en recesión ${ }^{61}$ o milagro social ${ }^{62}$ (Figura 2). México no ha sido la excepción al tiempo que suceden poblamiento versus despoblamiento de lugares de origen y expuestos a una política restrictiva en los países centrales (Europa, Estados Unidos...) y su incertidumbre en la participación en los procesos electorales, específicamente en Estados Unidos, a la vez que ha implicado grandes costos para México. ${ }^{63}$

Mientras que a nivel nacional se estimaba que los migrantes enviaron a México cerca de 40 mil millones de dólares, al Estado de México ingresaron 2.1 mil millones de dólares. A la vez que tenemos ligero descenso del primer trimestre al segundo estimado en -6.6 por ciento y -5.2 por ciento en relación al trimestre de abril-junio de 2019 (Figura 3).

\section{CONSECUENCIAS Y RIESGOS ECONÓMICOS DE LA INMOVILIDAD POR COVID-19 EN EL MUNDO Y MÉXICO}

La Covid-19 hundió al sistema económico mundial en una crisis económica, la que ha sido la peor recesión desde 1929 o la segunda Guerra Mundial. ${ }^{64}$ Más de medio mundo sufre un parón (inmovilidad) sanitario de la producción (es decir, también se inmovilizó la economía), el comercio y los servicios, por ejemplo, condujo a la caída internacional del precio del petróleo (la cual surgió de una guerra entre Rusia, Arabia Saudita y Estados Unidos como fondo la sobreproducción) se asoció al brote del Covid-19 y hasta abril 8 del 2020, los analistas plantean un escenario extremo: la caída del petróleo a cero dólares. ${ }^{65}$

\footnotetext{
${ }^{60}$ Véase en "Nuevo récord de remesas: 38 mil mdd en 12 meses", consultado en https://www. jornada.com.mx/ultimas/economia/2020/09/02/nuevo-record-de-remesas-38-mil-mdd-en-12meses-7773.html (04/09/2020).

${ }^{61}$ Véase en "Las remesas que salvan al país: "sin ese dinero, me habría quedado sin comer", consultado en https://www.razon.com.mx/negocios/benditas-remesas-salvando-pais-ese-dinerome-habria-quedado-comer-402746 (19/10/2020).

${ }_{62}$ Véase en "¿Qué dijo AMLO sobre la economía mexicana en su mensaje por los dos años de gobierno?", consultado en https://www.eleconomista.com.mx/politica/Que-dijo-AMLO-sobrela-economia-mexicana-en-su-mensaje-por-los-dos-anos-de-gobierno-20201201-0096.html $(02 / 12 / 2020)$.

${ }^{63}$ Véase en "El precio que pagó México para ayudar a Trump a contener éxodo migratorio", consultado en https://www.jornada.com.mx/sin-fronteras/2020/09/08/el-precio-que-pagomexico-para-ayudar-a-eu-a-contener-exodo-migratorio-137.html (09/09/2020).

${ }^{64}$ Véase en "La Covid-19 (coronavirus) hunde a la economía mundial en la peor recesión desde la Segunda Guerra Mundial", consultado en https://www.bancomundial.org/es/news/press-release/2020/06/08/covid-19-to-plunge-global-economy-into-worst-recession-since-world-war-ii $(09 / 09 / 2020)$.

${ }_{65}$ Expansión, 2020, Los analistas plantean un escenario extremo: la caída del petróleo a cero dólares, consultado en https://www.expansion.com/mercados/materias-primas/2020/03/19/5e736c56468aeb58118b4641.html (30/04/2020).
} 
Los riesgos de la vulnerabililad sociodemográfica por el Covid-19 en México 2020 / J.G. GONZÁLEZ y B.J. MONTOYA

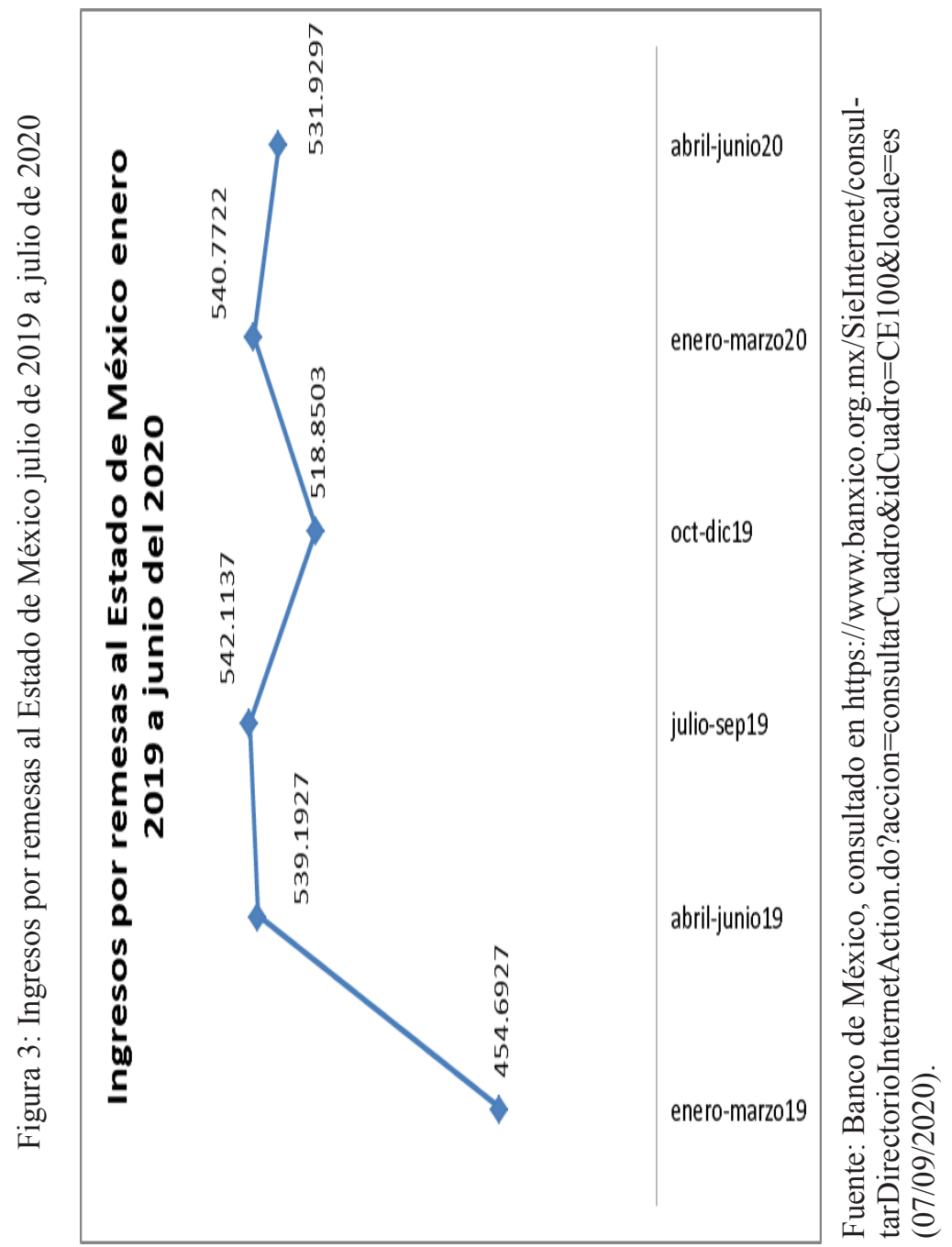


En cuanto a la caída del crecimiento económico del mundo en 2020, el Banco Mundial proyecta que será de -5.2 por ciento, para los países desarrollados se estima en menos siete por ciento y para las economías emergentes y en desarrollo su tasa será en -2.5 por ciento.

Obviamente, con grandes diferencias entre un país y otro, por ejemplo, para América Latina tendrá una caída de 7.2 por ciento (los países con mayor caída en su PIB será Belice y Perú) y para México será de 7.5 por ciento, producto de la inmovilidad, la producción de los diferentes sectores económicos denominados no necesarios. ${ }^{66}$ Aunque recientemente la Organización para la Cooperación y el Desarrollo Económico (OCDE) sostiene que la economía mexicana caerá en 10.2 por ciento ${ }^{67}$ y su crecimiento en 2021 será mayor a tres por ciento. Las estimaciones originales y oportunas se pueden revisar en la página del INEGI en el cual podemos apreciar la gran caída del PIB por sectores económicos y su recuperación en forma de $U \cdot{ }^{68}$

El freno y caída de la economía mundial por el confinamiento o inmovilidad perturbó a los sectores primario (crisis alimentaria), secundario (muchas industrias pararon y por consiguiente hubo desplomes históricos de su actividad económica) y terciario. ${ }^{69}$ Causa la caída del comercio mundial (con déficit en la balanza de pagos, caída de la venta de comerciantes grandes y los pequeños emprendedores han sido abandonados a su suerte). La crisis sanitaria-económica influyó en la pérdida de empleos, ${ }^{70}$ en el aumento del desempleo y la de trabajadores por cuenta propia e informalidad, despido de profesionistas, tropiezos en la inversión extranjera directa (inversión en activos fijos), la inversión pública, la caída de los ingresos de los trabajadores, despidos, la caída del precio del petróleo a nivel internacional, aumento de solicitudes al seguro de desempleo en países desarro-

\footnotetext{
66 Véase en "Perspectivas económicas mundiales", consultado en http://pubdocs.worldbank.org/en/657071588788309322/Global-Economic-Prospects-June-2020-Regional-Overview-LAC-SP.pdf (11/09/2020).

67 Véase en "OCDE prevé mayor caída del PIB de México para 2020", consultado en https:// www.forbes.com.mx/economia-ocde-prevision-pib-mexico-2020/ (18/09/2020).

68 Váse en "Estimación Oportuna del PIB trimestral", consultado en https://www.inegi.org.mx/ temas/pibo/ (20/11/2020).

${ }^{69}$ Véase en "Resultados y daños del Covid-19 en la economía mexicana", consultado en https:/www.eleconomista.com.mx/sectorfinanciero/Resultados-y-danos-del-Covid-19-en-laeconomia-mexicana-20200528-0029.html (11/09/2020). También en "Estimación Oportuna del PIB trimestral", consultado en https://www.inegi.org.mx/temas/pibo/ (21/10/2020).

${ }^{70}$ La inmovilidad de la actividad económica condujo a la caía de la economía trajo consigo la pérdida de empleo en el mundo y México. México recupera el 65\% de los 12 millones de empleos perdidos durante la pandemia. La tendencia a la recuperación se reafirma con la vuelta de 608 mil personas al mercado laboral en agosto, pero las cifras siguen lejos del escenario anterior a la crisis, consultado en https://elpais.com/mexico/2020-09-28/mexico-recupera-el-65-de-los12-millones-de-empleos-perdidos-por-la-pandemia.html (28/09/2020).
} 
llados, crisis alimentaria, etcétera. A la vez, se reconoce el incremento de la pobreza a nivel mundial, ${ }^{71}$ en América Latina ${ }^{72}$ y México. En nuestro país, se sostiene que en la pobreza extrema caerán entre 12.3 y 18 millones, es decir, pasarían a la pobreza hasta 16.4 millones de personas en México. ${ }^{73}$

La educación y el coronavirus; el sistema educativo respondió a las sugerencias de la Organización Mundial de la Salud (OMS) al suspender actividades en todo el mundo (es decir, se inmovilizó la actividad educativa), según la Organización de las Naciones Unidas para la Educación, la Ciencia y la Cultura (UNESCO), más de mil millones de estudiantes y jóvenes de todo el mundo fueron afectados por el cierre de escuelas y universidades debido al brote del Covid-19 y cuyas clases se llevaron a cabo vía on line, lo mismo ocurrió para nuestro país del 19 de marzo al 19 de abril de 2020. La UNESCO reconoció que el brote y rebrote del Covid-19 es un problema sanitario de gran magnitud que afectó y puso en una gran crisis a la educación. ${ }^{74}$

Los efectos multidimensionales y sistémicos del Covid- 19 van mucho más allá de los que aquí se exponen. Amenaza con tener millones de trabajadores que quedarán sin seguridad social por el coronavirus $\mathrm{y}$, como hemos citados antes, revela con crudeza las desigualdades y puede agravarlas; a la vez es un evento mediático, que plantea retos a los epidemiólogos en la red, a la vez deja secuelas de paranoia social, discriminación; una Iglesia sin limosnas... y sin ingresos; pueblos que rechazan a migrantes provenientes de países en desarrollo e incluso de Estados Unidos tras huir del Covid-19; desafíos para trabajadores de la salud que son víctimas del miedo a la pandemia y poco reconocimiento a su trabajo y dedicación al

\footnotetext{
71 Para 2021, por cada 100 hombres jóvenes que vivan en pobreza extrema habrá 118 mujeres. Las mujeres asumen la mayor parte de la responsabilidad del cuidado de la familia, ganan menos, ahorran menos y tienen trabajos mucho menos seguros, una situación que se ha intensificado con la crisis del coronavirus, consultado en https://news.un.org/es/story/2020/09/1479872 $(05 / 10 / 2020)$.

72 En ese contexto, la CEPAL proyecta que el número de personas en situación de pobreza se incrementará en 45,4 millones en 2020, con lo que el total de personas en esa condición pasaría de 185,5 millones en 2019 a 230,9 millones en 2020, cifra que representa el 37,3\% de la población latinoamericana. Dentro de este grupo, el número de personas en situación de pobreza extrema se incrementaría en 28,5 millones, pasando de 67,7 millones de personas en 2019 a 96,2 millones de personas en 2020 , cifra que equivale al $15,5 \%$ del total de la población. Consultado en https://www.cepal.org/es/comunicados/contraccion-la-actividad-economica-la-region-se-profundiza-causa-la-pandemia-caera-91 (05/10/2020).

${ }^{73}$ Edgar Juárez, BBVA: Pasarían a la pobreza hasta 16.4 millones de personas en México, consultado en https://www.eleconomista.com.mx/economia/BBVA-Pasarian-a-la-pobreza-hasta-16.4-millones-de-personas-en-Mexico-20200522-0020.html (30/05/2020).

${ }^{74}$ UNESCO, 2020, Coalición Mundial para la Educación, consultado en https://es.unesco.org/ covid19/globaleducationcoalition $(25 / 05 / 2020)$.
} 
cuidado de la salud de los enfermos por esta pandemia que para algunos es sindemia. ${ }^{75}$

El argumento anterior puede ser apoyado con la Tabla 7, la cual expresa la correlación de fallecer por Covid-19 en las 32 entidades federativas del país con los que sobreviven; su correlación es alta ( 0.88 por ciento), no así con el índice de marginación (IM18), pero sí con la población vulnerable por carencia sociales (VULCS18) (0.88); con los vulnerables por carencia de ingresos (VULy18) (0.88); pero también con los no pobres y los no vulnerables (PnoPnoV18) (0.86, lo cual es un indicativo que la pandemia no respeta clase social); con los ocupados en el tercer trimestres de 2020 (OcupaIII), los desocupados del tercer trimestre de 2020 (desoIII), los de la pobreza laboral (pobrelab) e, incluso, con el número de médicos por mil habitantes de las 32 entidades federativas (Tabla 7). Dichos indicadores, expresan la exposición al riego del sistema económico social por Covid-19 y su vulnerabilidad sistémica con independencia de los rezagos de algunas de las variables aquí incluidas.

\section{CAPACIDAD de RESPUESTA Y DESAFíos de las POLÍTICAS PÚBLICAS}

La población estaba (y está) en completa vulnerabilidad y poca capacidad de respuesta porque en su momento no se contaba con vacuna alguna. La única respuesta fue la inmovilidad (confinamiento), a la vez que ningún gobierno podía detectar a todos los infectados, medían lo que se podía para estimar la tendencia y el contagio real a nivel mundial, nacional o local. A la vez que surgieron argumentos como el siguiente: la sociedad rebasó a AMLO (Andrés Manuel López Obrador). Pero la respuesta del Gobierno mexicano fue la instrumentalización de diversos protocolos de prevención, algunas medidas económicas, garantizar la protección a adultos mayores y grupos de riesgo; se suspendieron las clases presenciales; se suspendieron los eventos y reuniones masivos; se suspendieron las actividades laborales para cambiarlos por el Office Home; se recomendó mantener sana distancia social y física; se recomendó cuidar la higiene y la alimentación, así como se planteó y surgió la denominada solidaridad digital, etcétera.

Los medios de difusión se encargaron de exponer estas y otras tantas formas de cuidarse y prevenir la enfermedad en las vitrinas de la televisión, el Internet y otros medios de información existentes que, García Canclini,

\footnotetext{
${ }^{75}$ El término "sindemia" se refiere a problemas de salud sinérgicos que afectan la salud de una población en sus contextos sociales y económicos, Fernando Lolas Stepke, 2020, "Perspectivas bioéticas en un mundo en sindemia", consultado en https://scielo.conicyt.cl/scielo.php?script=sci_arttext\&pid=S1726-569X2020000100007 (21/10/2020).
} 
le denominó la dictadura sanitaria por el coronavirus y la vigilancia corporativa generalizada. ${ }^{76}$

Tabla 7: Tabla de correlaciones de fallecimientos por Covid-19

y riegos socioeconómicos, 2020

\begin{tabular}{|c|c|c|}
\hline & & falleció \\
\hline \multirow[t]{2}{*}{ falleció } & $\begin{array}{l}\text { Correlación de Pearson } \\
\text { Sig. (bilateral) }\end{array}$ & 1.00 \\
\hline & $\mathrm{N}$ & 32 \\
\hline \multirow[t]{3}{*}{ sobrevive } & Correlación de Pearson & $0.883^{* *}$ \\
\hline & Sig. (bilateral) & 0.00 \\
\hline & & 32 \\
\hline \multirow[t]{2}{*}{ Vulcs18 } & Correlación de Pearson & $0.880^{* *}$ \\
\hline & $\begin{array}{l}\text { Sig. (bilateral) } \\
\text { N }\end{array}$ & 0.00 \\
\hline \multirow[t]{3}{*}{ VulY18 } & Correlación de Pearson & $0.882^{* *}$ \\
\hline & Sig. (bilateral) & 0.00 \\
\hline & $\mathrm{N}$ & 32 \\
\hline \multirow[t]{2}{*}{ PnoPnoV18 } & Correlación de Pearson & $0.865^{* *}$ \\
\hline & $\begin{array}{l}\text { Sig. (bilateral) } \\
\text { N }\end{array}$ & $\begin{array}{r}0.00 \\
32\end{array}$ \\
\hline \multirow[t]{3}{*}{ ocupaIII } & Correlación de Pearson & $0.828^{* *}$ \\
\hline & Sig. (bilateral) & 0.00 \\
\hline & $\mathrm{N}$ & 32 \\
\hline \multirow[t]{2}{*}{ DESOIII } & Correlación de Pearson & $0.897^{* *}$ \\
\hline & Sig. (bilateral) & $\begin{array}{r}0.00 \\
32\end{array}$ \\
\hline \multirow{3}{*}{ pobrelab } & Correlación de Pearson & $\begin{array}{r}32 \\
0.05\end{array}$ \\
\hline & Sig. (bilateral) & 0.80 \\
\hline & $\mathrm{N}$ & 32 \\
\hline \multirow[t]{3}{*}{ IM18 } & Correlación de Pearson & -0.27 \\
\hline & Sig. (bilateral) & 0.14 \\
\hline & $\mathrm{N}$ & 32 \\
\hline \multirow[t]{3}{*}{ medicox $1000 \mathrm{~h} 14$} & Correlación de Pearson & $0.714^{* *}$ \\
\hline & Sig. (bilateral) & 0.00 \\
\hline & $\mathrm{N}$ & 25.00 \\
\hline \multirow[t]{3}{*}{ meDespecia14 } & Correlación de Pearson & 0.33 \\
\hline & Sig. (bilateral) & 0.07 \\
\hline & $\mathrm{N}$ & 32 \\
\hline \multicolumn{3}{|c|}{$\begin{array}{l}\text { * La correlación es significante al nivel } 0,05 \text { (bilateral). } \\
\text { * La correlación es significativa al nivel } 0,01 \text { (bilateral). }\end{array}$} \\
\hline \multicolumn{3}{|c|}{$\begin{array}{l}\text { Fuente: elaboración propia con base: http://www.conapo.gob.mx/es/CONAPO/Datos_Abiertos_ } \\
\text { del_Indice_de_Marginacion; https://www.coneval.org.mx/coordinacion/entidades/Paginas/ } \\
\text { inicioent.aspx; https://www.inegi.org.mx/app/estatal/\#grafica; https://www.coneval.org.mx/ } \\
\text { Evaluacion/IEPSM/Documents/Derechos_Sociales/Diag_derecho_Salud_2018.pdf; https://www. } \\
\text { coneval.org.mx/Medicion/MP/Paginas/AE_pobreza_2018.aspx; https://www.coneval.org.mx/ } \\
\text { Medicion/Paginas/ITLP-IS_resultados_a_nivel_nacional.aspx; https://www.inegi.org.mx/temas/ } \\
\text { itaee/. }\end{array}$} \\
\hline
\end{tabular}

76 Antropología Urbana, 2020, García Canclini: la dictadura sanitaria por el coronavirus y la vigilancia corporativa generalizada, consultada en https://urbanalogia.blogspot.com/ 
Asímismo, Manuel Castells argumentó: "Enfrentamos desunidos la más grave amenaza que ha tenido la humanidad". ${ }^{77}$

En ese mismo tono, tenemos quienes sostienen que el mecanismo de mitigación o la sutil libertad de estar encerrados tal como le llama Fabrizio Mejía Madrid, el 8 de abril de 2020, provocó la inmovilidad sistémica que incluyó a peatones y automóviles en las ciudades de México, Tijuana y Guadalajara, ${ }^{78}$ "el Subsecretario de Salud de México, Hugo López-Gatell, señaló que mientras la zona metropolitana del Valle de México ha reducido sustancialmente su movilidad, en las ciudades como Guadalajara y Tijuana no han acatado estas medidas de contingencia sanitaria para combatir Covid-19".

En términos simples, la política seguida por los gobiernos para dar respuesta a la pandemia del Covid-19 es la de cerrar fronteras: política del proteccionismo. Obviamente, que lleva todos los elementos difusos del cuidado personal y familiar. Ya para el periodo postcovid-19, la ONU sugiere que es necesario adoptar medidas políticas integradas y a gran escala a fin de atenuar el impacto de la pandemia, centrándose en cuatro pilares: apoyar a las empresas, el empleo y los ingresos; estimular la economía y el empleo, proteger a los trabajadores en el lugar de trabajo; y recurrir al diálogo social entre el gobierno, los trabajadores y los empleadores para encontrar soluciones. ${ }^{79}$

\section{Comentarios Finales}

El enfoque de vulnerabilidad sociodemográfica permite un análisis dinámico, incluyente y contextual, lo cual permite construir un marco conceptual sólido en relación con la exposición y capacidad de respuesta ante la pandemia del Covid-19. La vulnerabilidad-riesgo-respuesta-inmovilidad permite entender la heterogeneidad de la población y su exposición a enfermarse, fallecer o migrar, y las causas de mayor impacto en el sistema demográfico del país y el mundo; asimismo permite identificar los requerimientos de una persona y familias para que ésta sea capaz responder al

\footnotetext{
77 Álex Rodríguez, Manuel Castells: "Enfrentamos desunidos la más grave amenaza que ha tenido la humanidad", consultado en https://www.lavanguardia.com/vida/20200406/48329582092/ enfrentamos-desunidos-la-mas-grave-amenaza-que-ha-tenido-la-humanidad-ningun-estudiante-va-a-perder-el-curso-por-razon-de-la-epidemia.html (19/08/2020).

${ }^{78}$ INFOBAE, 2020, Coronavirus: Tijuana y Guadalajara, las urbes que menos disminuyeron su movilidad para atemperar contagios, consultado en https://www.infobae.com/america/mexico/2020/04/16/coronavirus-tijuana-y-guadalajara-las-urbes-que-menos-disminuyeron-su-movilidad-para-atemperar-contagios/ (05/05/2020).

${ }_{79}$ El mundo del trabajo y el Covid-19: Cuáles son las medidas adoptadas por los países, consultado en https://www.ilo.org/global/about-the-ilo/newsroom/news/WCMS_741374/lang--es/ index.htm $(21 / 10 / 2020)$.
} 
riesgo y la política gubernamental que, como el caso de México se sostiene que le está apostando a la inmunidad del rebaño. Porque, en argumento del Canciller mexicano, Marcelo Ebrard "No volveremos a la normalidad. Necesitamos ir más allá, tener nuevas iniciativas para mantener la cooperación aún si ya no estamos en el punto más grave de la pandemia". ${ }^{80}$ Lo cual, significa que el riesgo futuro después del Covid-19, los expertos estiman que habrá rebrotes como la influenza pandémica de 1918 y 1919 que tuvo su primera, segunda y tercera ola. Pero, además, estará presente con nosotros tal como una gripa, como el sida, etcétera.

En términos sistémicos, aún con la vacuna, la pandemia del Covid-19, afectará al sistema demográfico: biológico (natalidad-mortalidad), social (emigración-inmigración $=$ inmovilidad) y tendrá consecuencias económicas, políticas, ambientales, culturales, tecnológicas y psicológicos (González et al., 2016).

Los datos apuntan a que tendremos una acentuación en la caída de la fecundidad debido a las difíciles condiciones económicas-salud derivado de la pandemia y un aumento de la mortalidad, pero sobre todo en ciertas cohortes de edad (por la salud de los mayores) y, principalmente masculinos. Ello asociados a enfermedades crónicas degenerativas, a la migración interna e internacional y a la acentuación de la pobreza.

Con lo que hemos revisado en este documento, compartimos los argumentos de la CEPAL, el cual sostiene que la enfermedad pone en riesgo a la salud humana, e impactará a una ya debilitada economía mundial y la afectará tanto por el lado de la oferta como de la demanda, ya sea a través de la interrupción de las cadenas de producción que golpeará severamente al comercio mundial. ${ }^{81}$

Para el caso del país, no es exagerado afirmar que la pandemia ha causado inmovilidad y ha tenido un fuerte impacto en la economía, reducción severa en el consumo, ademàs, las tensiones y las emociones negativas crecen ante un futuro incierto que genera polarización. Asimismo ha provocado efectos negativos en la escuela, las vacaciones, la seguridad, el medio ambiente, el acceso a la tecnología, la pobreza y las finanzas.

\footnotetext{
80 "No volveremos a la normalidad": Marcelo Ebrard destacó la importancia de la cooperación internacional ante crisis de Covid-19", consultado en https://www.infobae.com/america/ mexico/2020/11/13/no-volveremos-a-la-normalidad-marcelo-ebrard-destaco-la-importancia-de-la-cooperacion-internacional-ante-crisis-de-covid-19/ (13/11/2020).

${ }_{81}$ Véase en "Covid-19 tendrá graves efectos sobre la economía mundial e impactará a los países de América Latina y el Caribe", consultado en https://www.cepal.org/es/comunicados/ covid-19-tendra-graves-efectos-la-economia-mundial-impactara-paises-america-latina\#: :text=Explic $\%$ C3\%B3\%20que $\% 201$ \% $\% 20$ enfermedad $\% 20$ pone,severamente $\% 20$ al $\% 20$ comercio\%20mundial\%2D\%20como (21/10/2020).
} 
Por tanto, estamos ante uno de los desafíos más grandes de la humanidad en su dimensión demográfica, social, económica, tecnológica, ambiental y cultural, que para su entendimiento, nuestra narrativa requiere repensar e impensar el factor riesgo-vulnerabilidad y las respuestas individual, social y gubernamental existentes. Sobre esto último se ha planteado poner en marcha un plan similar al Plan Marshall para la reconstrucción sistémica del mundo de hoy ante las consecuencias de la pandemia del Covid-19. ${ }^{82}$

\section{REFERENCIAS BIBLIOGRÁFICAS}

Adsera, A. y Menendez, A., 2011, "Fertility changes in Latin America in periods of economic uncertainty", in Population studies, 65(1), pp.37-56, disponible en https://pubmed.ncbi.nlm.nih.gov/21213181/ Consultado el 05/02/2021.

Aparici, Roberto, 2010, Conectados en el Ciberespacio, disponible en https:// books.google.com.mx/books?id=JCB0jleuU_oC\&pg=PT268\&lpg=PT268\&d$\mathrm{q}=$ Netnograf $\% \mathrm{C} 3 \% \mathrm{ADa},+\mathrm{J} .+$ Redondas\&source $=$ bl\&ots $=$ rjKD_rEyRA\&si-

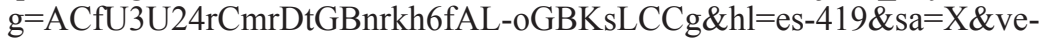
$\mathrm{d}=2$ ahUKEwjBnLf $x$ ProAhUFXqwKHWZ1AeEQ6AEwBHoECAoQAQ \#v=onepage \&q=Netnograf $\% \mathrm{C} 3 \% \mathrm{ADa} \% 2 \mathrm{C} \% 20 \mathrm{~J} . \% 20$ Redondas $\& \mathrm{f}=$ true. Consultado el 19/05/2020.

Araujo González, Rafael, 2015, "Vulnerabilidad y riesgo en salud: ¿dos conceptos concomitantes?”, en Revista Novedades de Población, vol.11 núm. 21, La Habana, ene.-jun., disponible en http://scielo.sld.cu/scielo.php?script=sci_arttext\&pi$\mathrm{d}=\mathrm{S} 1817-40782015000100007$ Consultado el 29/07/2020.

Armesilla Conde, Santiago Javier, 2018, ¿Es posible un transhumanismo marxista?, disponible en https://www.revistadefilosofia.org/82-02.pdf Consultado el 13/11/2020.

Beck, Ulrich, 1998, La sociedad del riesgo: Hacia una nueva modernidad, Paidós, México.

Bustamante, Jorge A., 2002, Migración internacionaly derechos humanos, UNAM, disponible en https://archivos.juridicas.unam.mx/www/bjv/libros/1/296/1.pdf Consultado el 29/07/2020.

Castro, M. C., Han, Q.C., Carvalho, L.R., Victora, C.G. y França, G.V.A., 2018, Implications of Zika virus and congenital Zika syndrome for the number of live births in Brazil, disponible en https://pubmed.ncbi.nlm.nih.gov/29844186/ Consultado el 26/08/2020.

CEPAL, 2020, Los riesgos de la pandemia de Covid-19 para el ejercicio de los derechos sexuales y reproductivos de las mujeres, disponible en https://oig.cepal. org/sites/default/files/folleto_ssyr_esp_0.pdf. Consultado el 02/01/2021.

82 Véase en "Cepal propone un 〈Plan Marshall〉 versión 2.0 para impulsar la recuperación de la crisis mundial", consultado en https://www.elfinanciero.com.mx/economia/cepal-proponeun-plan-marshall-version-2-0-para-impulsar-la-recuperacion-de-la-crisis-mundial (13/11/2020). 
CONAPRED, 2018, Epidemias en México, disponible en http://www.cenapred. gob.mx/es/documentosWeb/Tertulias/Presentacion_Ing.Maria_Ydirin.pdf Consultado el 31/08/2020.

González Becerril, Juan Gabino et al., 2016, Poblamiento y despoblamiento: dos caras de la desigualdad sociodemográfica en el Estado de México, disponible en https://repositorio.cepal.org/bitstream/handle/11362/40807/6/S1600764_es.pdf Consultado el 21/10/2020.

Hernández Sampiere, Roberto et al., 2014, Metodología de la investigación, sexta edición, Mc Graw Hill, disponible en https:/www.uca.ac.cr/wp-content/ uploads/2017/10/Investigacion.pdf Consultado el 13/11/2020.

Iranzo, Ángela, 2020, “Covid-19: ‘¿(in)seguridad sin (in)movilidad?’ Acercando la política de la movilidad a los Estudios Críticos de Seguridad, Geopolítica(s)", en Revista de estudios sobre espacio y poder, ISSN: 2172-3958, disponible en https://dx.doi.org/10.5209/geop.69120, revistas.ucm.es Consultado el 03/08/2020.

Lee, R., 1990, "The demographic response to economic crisis in historical and contemporary populations", in Population bulletin of the United Nations, (29):115, disponible en https://www.researchgate.net/publication/11111240_The_demographic_response_to_economic_crisis_in_historical_and_contemporary_populations. Consultado el $\overline{15} / 07 / 2020$.

Lima, E., Vilela, E., Peralta, A., Rocha, M. G., Queiroz, B. L., Gonzaga, M. R. y Freire, F., 2020, Exploring excess mortality in Latin America in the contexto of covid pandemic: the cases of Brazil and Ecuador, disponible en https://www. researchgate.net/publication/342432658_Exploring_excess_mortality_in_Latin_ America_in_the_context_of_covid_pandemic_the_cases_of_Brazil_and_Ecuador, Consultado el 15/12/20 $\overline{2} 0$.

Livi Bacci, Massimo, 1993, Introducción a la Demografía, Barcelona, Ariel.

Livi Bacci, Massimo, 2012, Historia mínima de la población mundial. Nueva edición ampliada y actualizada, España, Ariel.

Mandujano Sánchez, Angélica et al., 2003, Historia de las epidemias del México antiguo. Algunos aspectos biológicos y sociales, disponible en http://www.uam. $\mathrm{mx} /$ difusion/revista/abr2003/mandujano.pdf Consultado el 31/08/2020.

Márquez Morfín, Lourdes y Molina del Villar, América, 2009, El otoño de 1918: las repercusiones de la pandemia de gripe en la ciudad de México, disponible en http://www.scielo.org.mx/pdf/desacatos/n32/n32a10.pdf Consultado el 31/08/2020.

Marteleto, L.J., Guedes, G., Coutinho, R.Z. y Weitzman, A., 2020, "Live Births and Fertility Amid the Zika Epidemic in Brazil", en Demography, pp.1-30, disponible en https://www.ncbi.nlm.nih.gov/pmc/articles/PMC7895814/ Consultado el 05/02/2021.

Patiño, José Félix, 2020, Homo Deus, posthumanismo y transhumanismo, disponible en http://www.scielo.org.co/pdf/rcci/v35n1/2619-6107-rcci-35-01-00017. pdf Consultado el 13/11/2020. 
Postigo Solana, Elena, 2011, Transhumanismo y Post-humano: principios teóricos e implicaciones bioéticas, disponible en https://www.bioeticaweb.com/transhumanismo-y-post-humano-principios-teasricos-e-implicaciones-bioacticas/ Consultado el 13/11/2020.

Rodríguez Vignoli, Jorge, 2000, Vulnerabilidad demográfica: una faceta de las desventajas sociales, Serie, población y desarrollo Santiago de Chile, septiembre de 2000, Proyecto Regional de Población CELADE-FNUAP (Fondo de Población de las Naciones Unidas), Centro Latinoamericano y Caribeño de Demografía, (CELADE) - División de Población, disponible en https://repositorio.cepal.org/bitstream/handle/11362/7185/S2000937.pdf?sequence=1 Consultado el 29/07/2020.

Rodríguez, Jorge, 2004, Vulnerabilidad social y sociodemográfica: distinciones conceptuales, antecedentes empíricos y aportes de política. Taller sobre vulnerabilidad NEPO. CELADE, disponible en http://biblioteca.clacso.edu.ar/Argentina/ cea-unc/20100825121333/Lecturasvulnerabilidad.pdf Consultado el 29/07/2020.

Sánchez González, Diego y Egea Jiménez, Carmen, 2010, Reflexión sobre la vulnerabilidad social: concepto, enfoques, métodos y líneas de investigación, disponible en http://www.alapop.org/Congreso2010/DOCSFINAIS_PDF/ALAP_2010 FINAL141.pdf Consultado el 29/07/2020.

Stone, L., 2020, "Short-Run Fertility Responses to Mortality Events: A look to the past", in Applied Demography, v. 32, n. 01, abril 1, 2020, disponible en https:// webcache.googleusercontent.com/search? $\mathrm{q}=$ cache:d6AuG1AtELkJ:https://www. populationassociation.org/HigherLogic/System/DownloadDocumentFile.ashx\%3FDocumentFileKey\%3D8fda7948-e22c-6469-ba77-f4c0b5227c5b\%26forceDialog\%3D1+\&cd=2\&hl=es-419\&ct=clnk\&gl=mx. Consultado el 15/02/2021.

Torralba, Francesc, 2018, El Transhumanisme sota la lupa, disponible en http:// www.clubderoma.net/archivos/libros/OfCoRBen-2018-Libro-TranshumanismoBajolaLupa.pdf Consultado el 13/11/2020.

United Nations, 2019, World Population Prospects 2019, Department of Economic and Social Affairs, Population Division, custom data acquired via website, disponible en https://population.un.org/wpp/ Consultado el 27/10/2020.

\section{RESUMEN CURRICULAR DE LOS AUTORES}

\section{Juan Gabino González Becerril}

Maestro en Estudios de Población por El Colegio de la Frontera Norte. Es profesor-investigador de tiempo completo en el Centro de Investigación y Estudios Avanzados de la Población de la Universidad Autónoma del Estado de México (CIEAP/UAEM) y es director de la revista Papeles de Población editada por la misma institución.

Dirección electrónica: gonzalezg2012@hotmail.com 
Bernardino Jaciel Montoya Arce

Es Licenciado, Maestro y Doctor en Sociología por la Universidad Nacional Autónoma de México (UNAM). Pertenece al Sistema Nacional de Investigadores Nivel I, cuenta con Perfil Deseable PROMEP. Actualmente es Coordinador del Centro de Investigación y Estudios Avanzados de la Población de la Universidad Autónoma del Estado de México (CIEAP-UAEM). Entre sus publicaciones recientes se encuentran Demografía indígena en el Estado de México (coautor), 2013; Análisis demográfico del envejecimiento en el Estado de México (compilador), UAEM, 2011 y "La educación indígena en el Estado de México", en Papeles de Población, 2013.

Dirección electrónica:bjmontoyaa@uaemex.mx

Artículo recibido el 7 de enero de 2021 y aprobado el 29 de abril de 2021. 